\title{
Story Learning Test: Decelerated Learning and Accelerated Forgetting in Children with Epilepsy
}

\author{
Loretta van Iterson ${ }^{1,2}$ (D) \\ Received: 7 September 2019 /Revised: 25 September 2019 / Accepted: 1 October 2019/Published online: 13 November 2019 \\ (C) The Author(s) 2019
}

\begin{abstract}
Introduction Increasing interest is seen for early and late memory consolidation and accelerated forgetting, but little is known about these phenomena in children with epilepsy. The present study analysed the trajectory of learning and retention in typically developing children and children with epilepsy on a story learning test.

Methods 285 children, 126 typically developing children and 159 children with epilepsy, in ages between 4 and 10 years and Full-Scale IQs $\geq 75$, were given a specifically designed story learning test (iter-SEIN). The learning phase included Initial reading and a Free Recall trial with 10 Questions, and up to three repetition trials with Questions. Trials of Delayed Free Recall and Questions followed after half an hour, the next day and 1 week later. With several repeated measures analyses of variance, level of performance and gains or losses over time were analysed.

Results Age-dependent learning was seen after repetitions. On the Questions, typically developing children outperformed children with epilepsy increasingly, due to smaller gains after the second trial. Learned information was similarly preserved. Free Recall showed similar performance for both groups up to day 2. A week later, a conspicuous loss of information was observed in the children with epilepsy, whilst typically developing children retained the information. On index scores, reliable cognitive loss of information was seen in epilepsy in $24.5 \%$ of the children. Semantic neuropsychological tasks and severity measures of epilepsy were associated with level of performance.
\end{abstract}

Discussion The results provided evidence for early decelerated learning and late accelerated forgetting in children with epilepsy.

Keywords Children with epilepsy $\cdot$ Story memory $\cdot$ Accelerated long-term forgetting $\cdot$ Story telling

\section{Introduction}

Listening to and recalling a story are meaningful tasks which resemble attending to and remembering verbal information in everyday life (Lezak et al. 2004). Within Squire's taxonomy of memory, story tests are considered declarative verbal memory tasks (Squire and Knowlton 1997). Declarative memory is explicit and may be semantic or episodic. Semantic memory relates to factual knowledge and is necessary in language, whilst episodic memory is often autobiographical (Squire and Knowlton 1997; Tulving 1972). In the neuropsychological research literature, information learned during neuropsychological

Loretta van Iterson

lviterson@sein.nl

1 Department of Psychology, Stichting Epilepsie Instellingen Nederland (SEIN), PO Box 540, 2130AM Hoofddorp, Netherlands

2 School De Waterlelie, Cruquius, Netherlands testing, like word lists but also a story, is often considered to tap episodic memory (Rzezak et al. 2017; Smith and Lah 2011), whilst the term semantic memory is used for the retrieval of already acquired information like word knowledge, word fluency and repetition of sentences (Smith and Lah 2011). Due to their reliance on factual language content, however, story tests may also be considered as semantic memory tests (Cormack et al. 2012). Indeed, in factor-analytic studies, memory for stories has been found to load both on semantic and episodic memory (Smith and Lah 2011). As such, story tests may be understood as having both semantic and episodic components, episodic, given that they require new learning; semantic, because for their comprehension, they rely on already acquired information and language abilities. As stated by Tulving (1972), semantic and episodic memory may not be independent, and episodic memory formation may be influenced by information stored in semantic knowledge. Because of their combined aspect of listening and simultaneously understanding the story, some authors have considered story tests as working-memory tasks (Swanson et al. 2009). These studies suggest that story 
tests are more heterogeneous in nature than, for example, word lists, and therefore are likely to draw upon the integrity and wellfunctioning of the brain in the different stages of the formation of memories. Not surprisingly, story tests have been found to correlate highly with IQ (Swanson et al. 2009), especially in the initial learning phase, and semantic memory has been associated with scholastic performance, particularly reading comprehension (Lah and Smith 2014).

Children with epilepsy have an increased risk for memory problems (Menlove and Reilly 2015). When comparing children with epilepsy to typically developing children, studies have shown lowered memory scores on working memory, word lists and stories, irrespective of type of epilepsy (Gascoigne et al. 2012; Jambaqué et al. 1993; Lopes et al. 2014; Northcott et al. 2007; Rzezak et al. 2017; van Iterson and de Jong 2018). Some conflicting evidence has been found for effects of lateralisation of seizures in focal epilepsy. Worse performance in children with left versus right temporal lobe epilepsy on several measures, including immediate story recall, has been reported in by some authors (Jambaqué et al. 2007) but not others (Jocic-Jakubi and Nebojsa 2006). When comparing different types of epilepsy, frontal lobe epilepsy was found to lead to worse performance on list learning than childhood absence epilepsy or benign epilepsy with centrotemporal spikes (Lopes et al. 2014). In their extensive metaanalysis on memory in children with epilepsy, Menlove and Reilly (2015) concluded that the risks were largest with early age of seizure onset, longer duration of epilepsy, a greater number of anti-epileptic drugs and a higher number of seizures. Seizure freedom did not clearly affect test results (Menlove and Reilly 2015). After epilepsy surgery, both improvement and worsening of test scores have been observed (Lou Smith et al. 2006). Sex differences were seen on a story recall, suggesting an advantage for girls over boys (Smith et al. 2009).

In memory acquisition, encoding of information is rapidly followed by early consolidation already the same day (Baker and Zeman 2017). Indeed, studies generally test story retelling and delayed recall the same day, with an interval between immediate and delayed recall ranging from $10 \mathrm{~min}$ to half an hour or an hour, likely tapping this period of early consolidation (Cormack et al. 2012; Gascoigne et al. 2012; Jambaqué et al. 2009; Rzezak et al. 2012; Rzezak et al. 2017; Smith et al. 2009; Smith and Lah 2011). During this delay, after a single presentation, some loss of information occurs (Davidson et al. 2007; Jambaqué et al. 1993; Rzezak et al. 2012), referred to as normal retention.

Beyond early consolidation, there is increasing interest in the late consolidation of memory or, alternatively, the accelerated forgetting of the information (Baker and Zeman 2017). Accelerated long-term forgetting or ALF is defined as excessive loss of information with longer time intervals, which may be hours or weeks, given unimpaired memory acquisition and early consolidation during the first hour (Elliott et al. 2014; Helmstaedter et al. 2018; Ricci et al. 2015). Some authors have also used the term to indicate loss of information over time in subjects who already showed deficits in the acquisition and early consolidation and defined ALF as loss of the acquired information, greater than seen in control subjects (Helmstaedter et al. 2018). A difficulty encountered in the assessment of late consolidation is that no specifically developed tests for long-term memory are available (Elliott et al. 2014). Thus, in order to study late consolidation and accelerated long-term forgetting, studies have extended existing tests, often word lists, to include later recall sessions to later days, up to one or several weeks (Helmstaedter et al. 2018; Ricci et al. 2019).

Studies on accelerated forgetting have focussed on adults with temporal lobe epilepsy (see Elliott et al. 2014, for an extensive review). Studies in children are gradually emerging (Davidson et al. 2007; Gascoigne et al. 2012, 2014), but are still considered conspicuously scarce (Baker and Zeman 2017). Studies on ALF of word lists in children with idiopathic generalised epilepsy (Davidson et al. 2007; Gascoigne et al. 2012, 2014) concluded that ALF need not be restricted to adult focal epilepsy, but can also be found in children with IGE and temporal lobe epilepsy. Long-term forgetting was not associated with epilepsy severity (Gascoigne et al. 2014) and was less clearly seen when the number of presentations to learn to criterion was higher (Davidson et al. 2007). Longterm forgetting was seen especially in older children with epilepsy (Gascoigne et al. 2014), leading the authors to suggest that ALF may increase during the course of the epilepsy. Importantly, authors have highlighted that parents of children with epilepsy often reported long-term memory problems in their children (Grayson-Collins et al. 2019). These problems often remain undetected with standard memory tests on the first day, and may become evident only in tests including measures of accelerated long-term forgetting, and indicated that proper tools should be developed to capture these memory problems (Gascoigne et al. 2012).

These few studies have studied accelerated forgetting in an experimental setting, whilst studies including measures of long-term memory in standardised clinical assessment are virtually non-existent (Baker and Zeman 2017). The authors stress the clinical importance of knowledge on accelerated forgetting in children, given that in the educational setting, they are continuously exposed to information that must be remembered.

Other than in word list tests, which have several presentations or learning trials and allow the analysis of the learning curve (Vago et al. 2008), story tests generally provide a single presentation. The examiner reads a prose paragraph aloud a single time and asks for an immediate recall and for a delayed recall after some time the same day, as in the Wechsler Logical Memory (Wechsler 1984). In some cases, a set of question is 
used (Korkman et al. 2010); in a few cases, authors have also included repeated presentations as well as questions to test story acquisition and delayed recall, allowing to study forgetting also at short time intervals (Frisk and Milner 1990). Specific information on early and especially late consolidation in children with epilepsy is gradually emerging. On story retelling in children with epilepsy, however, studies are scarce or lacking.

The aim of the present work was to report on the performance on learning, early and late consolidation of memory on a short story in typically developing children and children with epilepsy. For this aim, a story telling test, called iterSEIN (van Iterson 2017), was specifically designed and developed for children in ages from 4 to 10 years, and included a story paragraph as well as a set of questions which were presented several times (learning trials). Delayed Free Recall and the Questions were retested after a short delay, the next day and 1 week later. The experimental test manual provides cutoff scores to indicate when reliable loss of information has occurred. The test is in its experimental version and data collection is still ongoing.

The present study aims at reporting on the memory curve in children in primary school age, both typically developing norm children as well as children with epilepsy. The study aims at addressing various suggestions increasingly recognised as important in the literature, particularly the need of specifically designed memory tests beyond the half-hour recall and increased knowledge on the long-term performance of children with epilepsy. For this purpose, a story test was specifically designed extending memory testing beyond the half-hour recall, to the next day or up to a week later. As such, the present study aims at studying early and late memory consolidation on a story learning task.

The study addressed the following research questions, based on the story learning test. The first research question is associated with the typically developing children only and may be considered as a preliminary question addressing the test characteristics, whilst all others focus on children with epilepsy: (1) Given up to four presentations of a story, and measuring free recall and answers to questions at various points, what changes on the learning curve across trials can be seen in typically developing children? What changes can be seen at delayed recall trials the same day (day 1), the next day (day 2) and a week later (day 7)? (2) Does the learning curve across trials differ between the group of typically developing children and the children with epilepsy? Given the repeated presentations during learning trials, do children with epilepsy experience accelerated forgetting beyond day 1 , at day 2 or day 7? (3) What is the rate of children presenting with reliable change of memory performance over time? (4) Can neuropsychological variables be identified associated with learning and forgetting? (5) Can epilepsy variables be identified associated with learning and forgetting?

\section{Methods}

Participants The sample comprised by 285 children between ages 4 years, 0 months and 10 years, 11 months with FullScale IQ's (FS-IQ) between 75 and 135. They had been given the iter-SEIN Story at day 1 with a delayed recall at day 1 as well as one or several days later (day 2, day 7 or both).

The sample of typically developing children consisted of $N=126$ children with delayed recall data came from the norm sample for the iter-SEIN Storytelling Test. The data were collected from children in regular primary schools as part of a larger standardisation study which aimed at collecting norm data for the iter-SEIN as the primary measure of interest. The standardisation sample comprised children for whom data collection was limited to day 1 or extended up to day 7; only children with data beyond day 1 were included in the present study. To ensure that the children had no developmental problems, together with the informed consent form, parents and teachers were asked to fill in a query relating to the child's development.

The children comprised in the present sample had a delayed recall at day 2 and day $7(n=97)$. Data on delayed recall on day 2 were present for virtually all children $(n=123)$, on day 7 , for $n=100$ typically developing children.

The sample with children with epilepsy consisted of $N=$ 159 children. From these, $n=110$ had a delayed recall on day 2 , and $n=49$ had a delayed recall on Day 7. They presented to the child neuropsychology department of the tertiary epilepsy centre SEIN for comprehensive neuropsychological evaluation because there were concerns about their cognitive development. They were tested either at the polyclinic or at the clinic. The data relate to observational data in standard clinical neuropsychological evaluation. Children tested in the polyclinic returned for the delayed recall session a day later (day 2: $n=41$ ) or several days later, generally after a week (day 7 : $n=49)$. The children who were tested in the clinic came from the Child Epilepsy Centre (KEC), a 24-h multidisciplinary diagnostic programme which included a 24 -h video EEG with concomitant neuropsychological testing. All these children had the delayed recall on day $2(n=69)$. If children had undergone neuropsychological testing more than once, only the first evaluation containing the iter-SEIN Storytelling Test was included in the sample. Epilepsy-related variables came from neurological or neuropsychological reports. Tables 1 and 2 provide the descriptive information of the samples.

\section{Test Instruments/Measures}

Story Telling Test In the story telling test iter-SEIN (van Iterson 2017), the child listens to a short Dutch prose text and is asked to retell the story immediately (Initial Free Recall). Then, 10 questions are presented to the child, which follow the course 
Table 1 Descriptives of the samples and comparison between the typically developing children and the children with epilepsy. Within epilepsy, comparison of the subset with Delayed Recall at day 2 (DR Day 2) versus Delayed Recall at day 7 (DR Day 7 )

\begin{tabular}{|c|c|c|c|c|c|c|}
\hline & Typically developing & Epilepsy & $p$ & $\begin{array}{l}\text { Epilepsy subset } \\
\text { DR Day } 2\end{array}$ & $\begin{array}{l}\text { Epilepsy subset } \\
\text { DR Day } 7\end{array}$ & $p$ \\
\hline $\mathrm{N}$ & 126 & 159 & & 110 & 49 & \\
\hline Age in years, mean (SD) & $7.7(1.8)$ & $8.0(1.5)$ & .194 & $8.0(1.6)$ & $8.1(1.4)$ & .661 \\
\hline Age range (years) & $4.2-10.9$ & $4.1-10.8$ & & $4.1-10.8$ & $4.8-10.6$ & \\
\hline Sex, $N$ boys (\%) & $55(43.7)$ & $88(55.3)$ & .050 & $61(55.5)$ & $26(53.1)$ & .780 \\
\hline FS-IQ, mean (SD) & $102.5(12.6)$ & $93.3(11.7)$ & $<.001$ & $92.6(11.7)$ & $91.1(11.7)$ & .208 \\
\hline $\mathrm{KEC}, N(\%)$ & - & $69(43.4)$ & & $69(62.7)$ & 0 & \\
\hline
\end{tabular}

KEC participation in Child Epilepsy Centre. FS-IQ in control group based on $n=110$. Comparisons with $t$ test or chi-square

of the story closely (Q1). Thereafter, three more learning trials are provided: the story is repeated three times to the child, each time followed by the same set of questions (Q2, Q3 and Q4). The maximum number of presentations is 4 . The minimum number of presentations is 3 ; if $\geq 90 \%$ of the questions is answered correctly, the testing may be limited to 3 trials, but in clinical assessment it is encouraged to present all trials. Various delayed recall trials follow, each with a free recall of the story and the same set of questions. These delayed recall trials are given after a short interval of 20 to $30 \mathrm{~min}$ (F.DR Day 1 for the Delayed Free Recall Day 1, and Q.DR Day 1 for the Questions Delayed Recall Day 1), the next day (Delayed Free Recall Day 2, F.DR Day 2 and Q.DR Day 2 for Questions Delayed Recall Day 2), after a week (Delayed Free Recall Day 7, F.DR Day 7 and Q.DR Day 7) or both at day 2 and day 7. Figure 1 gives a schematic overview of the presentations and the recall trials. In order to allow retesting in a clinical setting, the iter-SEIN provides for two alternate versions, (van Iterson 2017), story A and story B, which were used interchangeably. Originally, the stories were translated and adapted to suit children from the Morris alternate paragraphs of the logical memory test (Morris, Kunka, \& Rossini, 1997) and complemented with the questions (Broekhuis 2006). Each story comprises 24 scorable fragments of information (maximum 24 points), each set of questions may lead to a maximum of 10 points; the story was administered and scored as described in the test manual. The test is normed for typically developing Dutch children in ages 4 to 10 years. The manual allows for age-corrected conversion of the raw scores of each trial in standard scores (mean $=10, \mathrm{SD}=3$ ). In addition, index scores (deviation quotients with a mean $=100$, $\mathrm{SD}=15$ ) are provided for the total performance on the learning phase at day 1 (Learning Index), and at each recall trial (Delayed Recall Index at day 1, day 2 and day 7). The index scores are composite scores of the standard scores for the Free
Recall and the Questions. For the Learning Index, the composite is based on the standardised Initial Free Recall and the standardised sum of Q1 to Q4. The various Recall Indexes are based on the standardised Free Delayed Recall and the standardised Delayed Recall of the Questions. Also, the manual provides critical $90 \%$ confidence interval cut-off scores for differences between trials or between index scores in order to determine whether a statistically meaningful (i.e. reliable) change has occurred between testing trials in an individual child. For the difference (1) between Learning Index and the Delayed Recall Index at day 1, cut-off is 23 points, (2) between Delayed Recall Index at day 1 and Delayed Recall Index at day 2, cut-off is 17 points, and (3) Delayed Recall Index at day 1 and Delayed Recall Index at day 7, cut-off is 18 points.

The iter-SEIN manual (van Iterson 2017) reports overall satisfactory psychometric properties in terms of reliability and construct validity. Interrater reliability was high ( $r$ s ranged from 0.94 to 0.96 ). Internal consistency, as measured by Cronbach's alpha, was sufficient. For story A (story B in brackets), alpha was $0.66(0.74)$ for the Initial Free Recall and $0.63(0.82)$ for the Delayed Free Recall; for the Questions, they ranged from $0.50(0.53)$ to $0.66(0.77)$, with increasing values for later trials. Pearson's product moment correlations between the two test versions ranged from 0.60 to 0.84 for the Free Recall trials. Spearman's rho for the questions trials ranged from 0.53 to 0.83 ; mean differences on the questions showed $p$ values $\geq$. 900 .

Intelligence Testing To estimate the intellectual level of the children, they were tested with an age-appropriate version of the Wechsler scales of intelligence, the WPPSI-III ${ }^{\mathrm{NL}}$, the WISC-III $^{\mathrm{NL}}$ or WISC-V ${ }^{\mathrm{NL}}$ (Wechsler 2005, 2009, 2018), using a full form or a screening with a four-subtest WISC$\mathrm{III}^{\mathrm{NL}}$ short form which had been previously tested for its 
Table 2 Epilepsy variables. Descriptive data and comparison between subset with Delayed Recall at day 2 (DR Day 2) versus Delayed Recall at day 7 (DR Day 7)

\begin{tabular}{|c|c|c|c|c|}
\hline Epilepsy variables & $\begin{array}{l}\text { Epilepsy } \\
\text { Total }\end{array}$ & $\begin{array}{l}\text { Epilepsy subset } \\
\text { DR Day } 2\end{array}$ & $\begin{array}{l}\text { Epilepsy subset } \\
\text { DR Day } 7\end{array}$ & $\begin{array}{l}\text { Day } 2 \text { vs day } 7 \\
p\end{array}$ \\
\hline Age at onset of epilepsy in years $(n=155)$, mean (SD) & $4.5(2.4)$ & $4.4(2.5)$ & $4.7(2.3)$ & .529 \\
\hline \multirow[t]{2}{*}{ Duration of epilepsy up to test, mean (SD) } & $3.5(2.3)$ & $3.6(2.3)$ & $3.4(2.2)$ & .596 \\
\hline & $N(\%)$ & $N(\%)$ & $\mathrm{N}(\%)$ & \\
\hline Generalised seizures & $43(27.0)$ & $27(24.5)$ & $16(32.7)$ & .288 \\
\hline \multicolumn{5}{|l|}{ Focal onset seizures } \\
\hline Right lateralised focal onset seizures & $18(11.3)$ & $13(11.8)$ & $5(10.2)$ & .767 \\
\hline Left lateralised focal onset seizures (LH) & $22(13.8)$ & $15(13.6)$ & $7(14.3)$ & .913 \\
\hline Bilateral/ uncertain & $60(37.7)$ & $42(38.2)$ & $18(36.7)$ & .862 \\
\hline Unknown/missing & $16(10.1)$ & $13(11.8)$ & $3(6.1)$ & .939 \\
\hline Frontal & 19 (11.9) & $13(11.8)$ & $6(12.2)$ & .939 \\
\hline Temporal & $33(20.8)$ & $20(18.2)$ & $11(26.5)$ & .231 \\
\hline Parietal & $17(10.7)$ & $11(10.0)$ & $6(12.2)$ & .672 \\
\hline Occipital & $12(7.5)$ & $7(6.4)$ & $5(10.2)$ & .397 \\
\hline Central & $20(12.6)$ & $10(9.1)$ & $10(20.4)$ & .047 \\
\hline MRI + & $15(9.4)$ & $12(10.9)$ & $3(6.1)$ & .340 \\
\hline \multicolumn{5}{|l|}{ Number of AEDs used $(n=158)$} \\
\hline AEDs used: 0 & $48(30.4)$ & $33(30.0)$ & $15(31.3)$ & \\
\hline AEDs used: 1 & $69(43.7)$ & $48(43.6)$ & $21(43.8)$ & .950 \\
\hline AEDs used: $\geq 2$ & $41(25.9)$ & $29(26.4)$ & $12(20.0)$ & \\
\hline History of SE & $15(9.4)$ & $8(7.3)$ & $7(14.3)$ & .162 \\
\hline History of CSWS & $17(10.7)$ & $12(10.9)$ & $5(10.2)$ & .894 \\
\hline Inactive epilepsy & $26(16.4)$ & $19(17.3)$ & $7(14.3)$ & .638 \\
\hline Epilepsy syndrome severity $(n=140)$, mean (SD) & $5.4(2.0)$ & $5.4(1.9)$ & $5.3(2.2)$ & .886 \\
\hline Epilepsy syndrome severity & $2-10$ & $2-10$ & $2-9$ & \\
\hline
\end{tabular}

Frontal represents frontal involvement in seizure onset. Frontal involvement may be in combination with another lobe, as in fronto-temporal. Temporal, parietal, occipital and central involvement seizure onset are used in an analogous way to frontal. $M R I+$ positive findings on neuroimaging (versus negative findings on MRI or no MRI available), AEDs anti-epileptic drugs used at time of neuropsychological testing, $S E$ status epilepticus, CSWS continuous spike and waves during slow sleep which may also include children with a spike wave index between 50 and $80 \%$. Inactive epilepsy means no seizures reported in 12 months previous to testing. DR Day 2 Delayed Recall at day 2, DR Day 7 Delayed Recall at day 7.Comparisons with $t$ tests or chi-square

applicability also for the clinical group with epilepsy (van Iterson et al. 2015). For 16 (12.7\%) of the typically developing children, no FS-IQ was present.

Neuropsychological Variables Various neuropsychological measures, aimed at assessing semantic knowledge, confrontational naming, verbal fluency, short-term memory and working memory, were included. Except for the WISC-III ${ }^{\mathrm{NL}}$ subtest Vocabulary, which derives its norms from the test manual, the tests were all co-normed with the norm group of the iterSEIN. Based on the data collected on the norm group, raw scores were transformed into age-adjusted standard scores (mean $=10, \mathrm{SD}=3$ ). As a measure of rapid confrontational naming, the Dutch Lindeboom was used. This brief test requires rapid naming of 15 common coloured pictures displayed on three rows on a sheet of paper. Time to complete the task (in seconds) is measured, together with number of correctly named words; only time to complete the task was used in this study. As measures of verbal fluency, the amount of animals and verbs named in $60 \mathrm{~s}$ were taken and combined into a single measure. From the WISC-III ${ }^{\mathrm{NL}}$ subtest Digit Span, the longest series of digits correctly repeated forward was taken as a measure of short-term memory, the longest series of digits correctly repeated backward was taken as a measure of working memory (van Iterson and de Jong 2018).

\section{Epilepsy Variables}

Epilepsy-related variables came from neurological reports. The children comprised a heterogeneous clinical sample of children with epilepsy. Epilepsy and seizure type, localisation and lateralisation of seizures were based on seizure semiology 


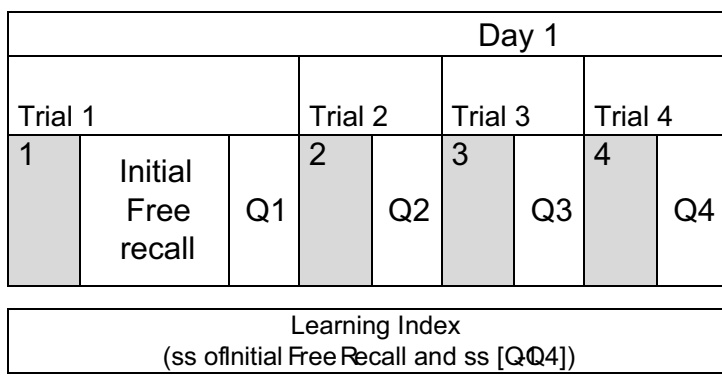

Fig. 1 Design and time line of the iter-SEIN Story test trials. Shaded areas denote presentations (read aloud by the examiner); white areas denote oral recall trials for the child. Recall may be Free $(\mathrm{F})$, Recall or with Questions (Q); recall may be Immediate (Initial Free Recall and Q1 to Q4) or Delayed (DR). The learning phase comprises the four

and (video) EEG-monitoring; if pertinent, results from neuroimaging. Epilepsy variables included age at onset of epilepsy, duration of epilepsy up to testing, generalised seizures (generalised versus focal or not determined), lateralisation of epilepsy (involvement of left hemisphere versus right hemisphere or not determined), localisation of epilepsy (involvement of the frontal, temporal, parietal, occipital or central brain area in the epilepsy, which could occur as single lobe seizure onset or in combination, as in centro-temporal seizures). Presence of abnormalities on brain neuroimaging (MRI+, versus MRI- or no MRI available); a history of status epilepticus ( $\mathrm{SE}+$, versus no SE reported in history), a history of night-time epileptic activity on the EEG with continued spike and waves during slow sleep (CSWS reported, versus no CSWS reported), and number of anti-epileptic drugs (AEDs) taken were also included, as well as inactive epilepsy (no seizures in the 12 months previous to testing, versus active epilepsy). As a general measure of severity, epilepsy syndrome severity ranging from 1 to 10, with 10 as the most severe score, was included (Dunn, Buelow, Austin, Shinnar, \& Perkins, 2004). Table 2 presents the data on epilepsy variables.

\section{Missing Data Analyses}

For the iter-SEIN, data were included according to the testing procedures and criteria described and did not allow for missing data. Missing data on neuropsychological and epilepsy variables were replaced by the mean. Missing values were generally associated with the $12.7 \%$ typically developing children who had not taken the Wechsler scales. Multiple imputation pattern analyses and imputation of missing values was done, setting minimum percentage of missing data to 0.01 , iterations to 5 and using the automatic method to find the best fit. Correlations between the pooled imputations with the replacing values with the mean ranged from 0.94 to 0.99 (except verbal fluency, $r=0.87$ ), suggesting that replacing missing values with the mean for the group was appropriate. For verbal fluency, the values of the last iteration were used.

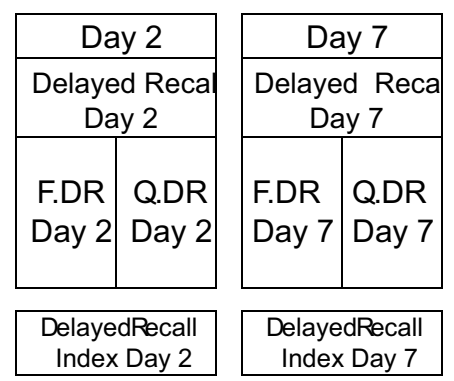

presentations and recall trials at day 1 . Delayed Recall Day 1 follows after half an hour, Delayed Recall Day 2 the next day, Delayed Recall Day 7 a week later. The last line indicates the trials included in the Index scores, which are based on age-adjusted standard scores

\section{Analyses}

The main statistical procedure used was repeated measures analysis of variance (ANOVA). The Free Recall scores and the Questions were analysed separately as dependent variables. The repeated measures procedure provides information on the level of performance (between-subject effects) as well as the progression across trials (within-subject effects). The shape of the curve across trials was studied with "polynomial contrasts" in the first analysis; the rate of change (gains or losses) from one trial to the next was studied with "repeated contrasts" in all analyses. To obtain insight in their possible effects, age, sex, story version, where appropriate, logarithmic ( $\log 10)$ number of days to last trial (Murre and Dros 2015), and participation in the KEC programme were included as covariates. Analyses were redone adding FS-IQ as a covariate. Wherever age-related differences were seen associated with change (within-subject effects), in order to interpret the relationship, the data were reanalysed splitting the sample into the younger (ages 4 to 7 years) and the older children (ages 8 to 10 years).

All within-subjects analyses in repeated measures ANOVA were preceded by Mauchly's test of sphericity. Mauchly's test indicated that the assumption of sphericity had been violated in all cases. Therefore, degrees of freedom were corrected using Greenhouse-Geisser estimates of sphericity. The values will be reported for the first analyses; Greenhouse-Geisser values were applied for all.

The inclusion of children with epilepsy from two sources, polyclinical and clinical (KEC) children, may potentially lead to flaws analogous to those known as "confounding by indication". It is conceivable that the reasons for having a child participate at the KEC programme may differ from the reasons to ask for a polyclinical evaluation. These might include random as well as non-random reasons. In addition, being tested whilst the EEG is running may add extra stress to the child. Therefore, where pertinent, the analyses were redone with the variable KEC (KEC participation versus participation in polyclinical setting) as a covariate. In addition, although the 


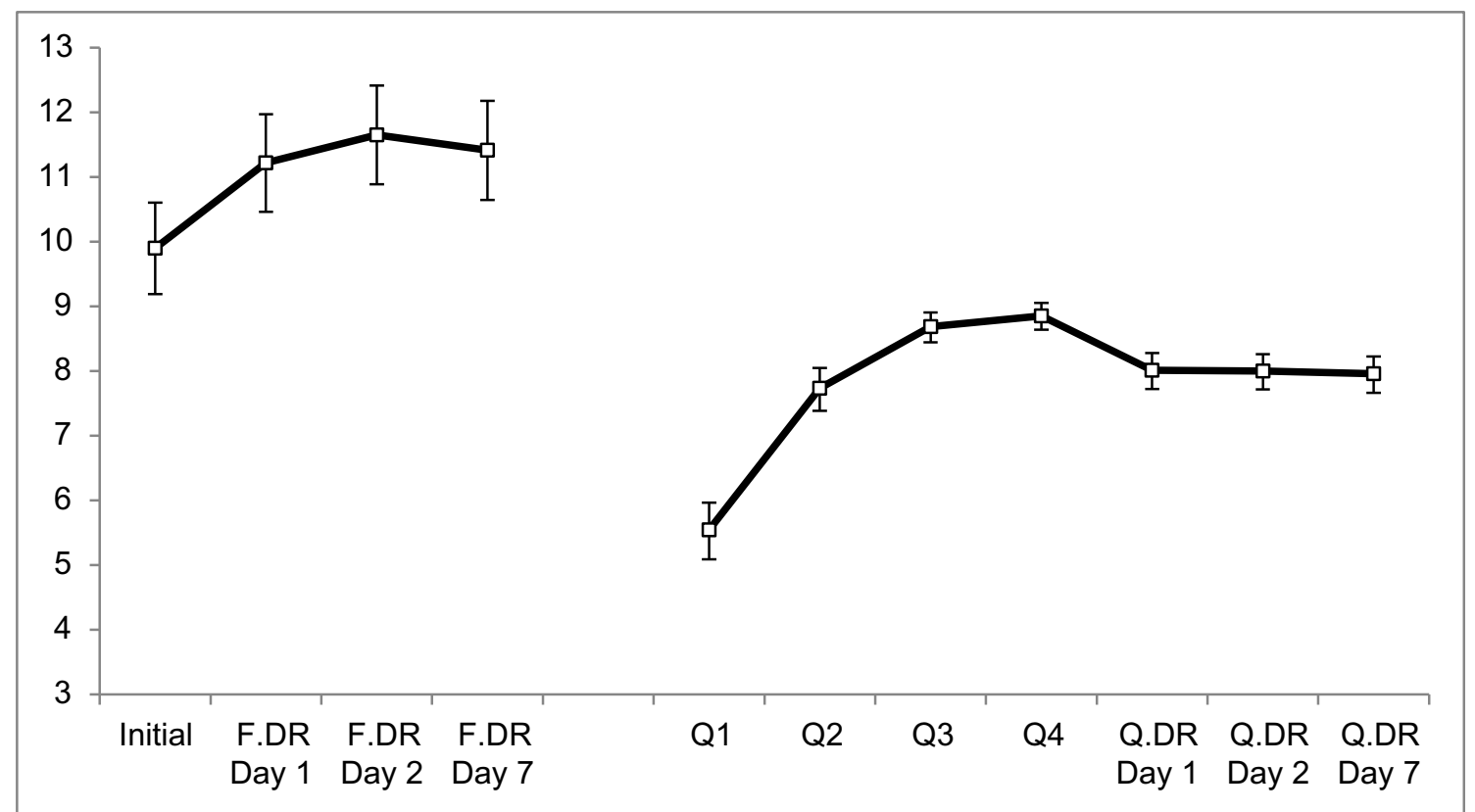

Fig. 2 Typically developing children $(n=96)$. Free Recall (left) and questions (right). Estimated raw means and $95 \%$ confidence intervals for day 1, day 2 and day 7. Adjusted for age, sex and story version. The $y$-axis denotes the raw mean number of points earned. For the free recall,

experimental test manual suggests that the two alternate test versions are equivalent, the analyses were controlled for story version.

To address the first research question and gain understanding of the curve of learning and remembering described across trials in the iter-SEIN, the analyses were first done with the typically developing children who had participated at all trials at day 1, day 2 and day 7 . These first analyses were conducted on the raw scores. The raw scores of the questions were subjected to reflection $(10+1,10$ being the maximum number of questions) followed by logarithmic (log 10) transformation. This was done because the subsequent presentation trials will be associated with more correct answers at later trials, thus leading to negatively skewed distributions. After the analyses, back-transformation was done in order to design Fig. 2 (right).

To address the second research question, analyses were based on age-adjusted standardised scores on the typically developing children and the children with epilepsy. Groups were contrasted entering group as the dependent variable.

Children with epilepsy had participated at day 1 and day 2 or day 7. Analyses were done on all trials at day 1 (learning and recall) as well as the last trial (either day 2 or day 7), with $\log 10$ adjustments for the precise number of days. Given that this comprehensive approach left out the intermediate values of the typically developing children (i.e. information on day 2 for children tested both at day 2 and day 7), additional, partitioned analyses were run for the children tested up to day 2 and those tested up to day 7 . Results of the partitioned the maximum is 24 points, corresponding with the 24 fragments on the story. For the questions, the maximum is 10 , corresponding with the 10 questions

analyses will be reported only wherever they provide additional or contrasting information.

In interpreting the main effects, alpha was adjusted depending on the number of independent variables entered (alpha = $0.050 / v$, where $v$ was the number of variables). No adjustments were required for the interpretation of planned comparisons.

The study of the third research question was based on the Learning Index and Delayed Recall Indexes at day 1, day 2 and day 7. Applying the cut-off scores for reliable change from the test manual, the rates of children showing reliable gains or losses was established and compared between the groups with chi-square.

For the fourth research question, the effect of neuropsychological variables was studied on the total sample of typically developing children and children with epilepsy, again using repeated measures ANOVA with repeated contrasts based on the index scores.

The fifth research question, concerning the effect of the various epilepsy variables, was addressed with generalised linear models (GLM) with normal probability distribution and identity link function. GLM were chosen, and Aikaike's information criterion (AIC) was applied, given the large number of epilepsy variables. GLM allows goodness-of-fit comparisons of various models after entering several variables at a time and AIC penalises for larger numbers of variables (Garson 2012). For the present purpose, GLM were done in parallel for the Learning Index and the Delayed Recall 
Indexes at day 1, and last day and all later models were compared with the base model. The base models included the variables sex and age (and for the last day, also log number of days) which were maintained in the later models. The second model included generalised seizure type, left hemisphere lateralisation and topographical localisation of brain areas involved in the seizures (frontal, temporal, parietal, central, occipital), all as dummy variables. The third model included measures of epilepsy severity (epilepsy syndrome severity, number of AEDs used, MRI+, reported SE+ or night-time epileptic activity in the child's history and active epilepsy. The fourth model included age at epilepsy onset and duration of epilepsy, and excluded age, given that age at onset and duration of epilepsy add up to age at testing. The final model was a parsimonious model, which included the variables which had shown to contribute significantly to the index $(p<.01)$ and to improve the base model applying AIC. Given the overall high similarities in the results, the same variables were entered for the final models for all indexes. The procedure was repeated for the changes between the index scores.

\section{Results}

Preliminary comparisons between the various groups will be presented first, followed by the results for the repeated measures for the typically developing children. Thereafter, the comparisons of the typically developing children with the children with epilepsy will be done. Rates of children with reliable cognitive change will be given. Finally, the contribution of neuropsychologial and epilepsy variables will be presented.

\section{Preliminary Testing}

Epilepsy Versus Typically Developing Children Independent samples $t$ test or chi-square (Table 1) revealed no differences between the typically developing children and the children with epilepsy in terms of background variables as age, sex or handedness. The typically developing children had higher mean IQ scores than the children with epilepsy. The mean number of presentations of the story for the typically developing children was $3.47(\mathrm{SD}=0.53)$, significantly lower $(p<.001)$ than for the children with epilepsy, 3.88 (SD = 0.33 ) (Table 3).

Comparisons Between Subsets Comparisons were made between the children who had been tested on day 2 versus day 7 (Tables 1 and 2), as well as between the children who presented at the polyclinic versus the KEC programme in the clinic (not shown). Independent samples $t$ tests or chi-square was done, as appropriate, and alpha set to 0.003 to adjust for the large number of comparisons. The comparisons did not reveal any differences in age, sex, mean number of presentations of the story, mean scores on the intelligence test. In addition, there were no differences on any of the epilepsy variables. Likewise, for the typically developing children, those who had been tested on day 7 also, or on day 2 only, did not reveal differences in background variables.

\section{Typically Developing Children and Children with Epilepsy}

\section{Typically Developing Children}

To address the first research question, the curve of learning and remembering or forgetting was analysed for the typically developing children who had participated at all trials at day 1 , day 2 and day 7. Figure 2 depicts the estimated means, as well as Bonferroni-corrected 95\% confidence intervals (CIs) for the Free Recall and the Questions, adjusted for age, sex and test version.

Free Recall in the Typically Developing Children Betweengroup effects based on the children who had completed all trials suggested large main effects for age $\left(F_{(1,93)}=147.0\right.$, $\left.p<.001, \eta_{\mathrm{p}}^{2}=0.61\right)$, with statistically significant effects on each of the four trials (Free Recall, Delayed Free Recall at day 1 , day 2 and day 7 ; all $p \mathrm{~s}<.001)$. No main effect was seen for sex $\left(F_{(1,93)}=1.8, p=.184\right)$ or test version $\left(F_{(1,93)}=\right.$ $0.2, p=.658)$.

For the within-subject effects, Mauchly's test of sphericity was significant, $\left(X^{2}{ }_{(5)}=21.5, p<.001\right)$ and degrees of freedom were corrected using Greenhouse-Geisser estimates of sphericity $(\varepsilon=0.58)$. No significant main effects were seen for age $(p=.070)$, sex $(p=.330)$ or test version $(p=.164)$. No particular information emerged on the shape of the curve. That is, the level of performance was generally maintained over the various trials.

Redoing the analysis after inclusion of FS-IQ led to overall similar results. Age-related effects were seen on all trials. Between-subject effects showed that level of performance was affected by IQ $\left(F_{(1,92)}=8.7, p=.004, \eta_{\mathrm{p}}^{2}=0.09\right)$ at all Free Recall trials ( $p$ s between 0.003 and 0.023 ), except DR Day $1(p=.071)$. Within-subject results were not dependent on IQ $(p=.631)$.

The Questions Based on the log 10 transformed raw scores on the questions, between-subject effects showed large age effects $\left(\mathrm{F}_{(1,93)}=127.3, p<.001, \eta_{\mathrm{p}}^{2}=0.58\right)$, with significant $p$ values at each of the 7 trials (all $p$ s $<.001$; at Q1 to Q4, Q.DR, Q.DR Day 2, Q.DR Day 7), but no significant effects of sex $\left(F_{(1,93)}=1.6, p=.210\right)$. Also, effects of test version were found $\left.F_{(1,93)}=4.4, p=.038, \eta_{\mathrm{p}}^{2}=0.05\right)$, suggesting slightly 
Table 3 Unadjusted mean scores on the iter-SEIN and neuropsychological variables. Comparison of the typically developing children (TD) and the children with epilepsy, comparison if the subset with epilepsy retested at day 2 and day 7; results of independent $t$ tests

\begin{tabular}{|c|c|c|c|c|c|c|}
\hline \multirow[t]{2}{*}{ iter-SEIN } & \multirow[t]{2}{*}{$\mathrm{TD}$} & \multirow[t]{2}{*}{ Epilepsy } & \multirow[t]{2}{*}{$p$} & \multicolumn{2}{|c|}{ Epilepsy subset } & \multirow[t]{2}{*}{$p$} \\
\hline & & & & DR Day 2 & DR Day 7 & \\
\hline & 126 & 159 & & 110 & 49 & \\
\hline Mean number of presentations & $3.47(0.5)$ & $3.88(0.3)$ & $<.001$ & $3.93(0.3)$ & $3.78(0.4)$ & .023 \\
\hline \multicolumn{7}{|c|}{ Learning and recall trials iter-SEIN (standard scores) } \\
\hline Initial Free Recall & $9.94(3.1)$ & $9.46(3.7)$ & .225 & $9.02(3.4)$ & $10.45(3.9)$ & .022 \\
\hline Questions 1 (Q1) & $10.01(2.7)$ & $9.28(2.8)$ & .039 & $9.01(3.3)$ & $9.88(2.8)$ & .114 \\
\hline Questions 2 (Q2) & $9.85(2.8)$ & $8.94(3.7)$ & .017 & $8.42(3.6)$ & $10.10(3.6)$ & .007 \\
\hline Questions 3 (Q3) & $8.94(3.7)$ & $8.28(3.6)$ & $<.001$ & $8.00(3.6)$ & $8.90(3.6)$ & .146 \\
\hline Questions 4 (Q4) & $10.02(2.6)$ & $8.31(3.6)$ & $<.001$ & $7.99(3.7)$ & $9.04(3.2)$ & .088 \\
\hline Delayed Free Recall Day 1 & $9.81(3.0)$ & $9.10(3.4)$ & .066 & $8.77(3.3)$ & $9.84(3.5)$ & .068 \\
\hline Questions DR Day 1 (Q.DR) & $9.96(3.0)$ & $8.43(3.7)$ & $<.001$ & $8.00(3.8)$ & $9.41(3.2)$ & .027 \\
\hline Delayed Free Recall Last Day & $9.79(2.8)$ & $8.25(3.4)$ & $<.001$ & $8.92(3.7)$ & $6.76(3.7)$ & .001 \\
\hline Questions DR Last Day & $10.00(2.4)$ & $8.60(3.4)$ & .001 & $8.73(3.3)$ & $8.31(3.6)$ & .474 \\
\hline Subset Delayed Recall Day 2 (n) & 123 & 110 & & & & \\
\hline Delayed Free Recall Day 2 & $10.38(2.7)$ & $8.92(3.0)$ & $<.001$ & & & \\
\hline Questions DR Day 2 (Q.DR Day 2) & $10.04(2.4)$ & $8.73(3.3)$ & .001 & & & \\
\hline Subset Delayed Recall Day 7 (n) & 100 & 49 & & & & \\
\hline Delayed Free Recall Day 7 & $9.84(2.8)$ & $6.76(3.7)$ & $<.001$ & & & \\
\hline Questions DR Day 7 (Q.DR Day 7) & $9.91(2.6)$ & $8.31(3.6)$ & .006 & & & \\
\hline \multicolumn{7}{|l|}{ Index scores } \\
\hline Learning Index & $99.1(14.8)$ & $92.3(18.7)$ & .001 & $89.9(18.3)$ & $97.6(18.6)$ & .016 \\
\hline Delayed Recall Index Day 1 & $99.3(14.7)$ & $92.9(17.8)$ & .001 & $90.7(17.8)$ & $97.8(16.8)$ & .019 \\
\hline Delayed Recall Index Last Day & $99.6(12.0)$ & $90.8(17.5)$ & $<.001$ & $93.1(16.4)$ & $85.6(19.0)$ & .012 \\
\hline Delayed Recall Index Day 2 & $101.2(12.8)$ & $93.1(16.4)$ & $<.001$ & $93.1(16.4)$ & & \\
\hline Delayed Recall Index Day 7 & $99.3(13.5)$ & $85.4(19.2)$ & $<.001$ & & $85.6(19.0)$ & \\
\hline \multicolumn{7}{|c|}{ Neuropsychological variables (standard scores) } \\
\hline Vocabulary & $10.3(2.7)$ & $9.4(2.7)$ & .003 & $9.1(2.8)$ & $10.0(2.3)$ & .050 \\
\hline Lindeboom Naming & $9.6(3.4)$ & $7.5(3.7)$ & $<.001$ & $7.2(3.7)$ & $8.3(3.5)$ & .088 \\
\hline Verbal Fluency & $20.1(4.8)$ & $15.4(5.9)$ & $<.001$ & $20.1(6.0)$ & $15.1(5.6)$ & .277 \\
\hline Digit Span Forwards & $10.4(2.5)$ & $8.0(2.9)$ & $<.001$ & $7.8(3.2)$ & $8.5(2.3)$ & .114 \\
\hline Digit Span Backwards & $10.0(2.8)$ & $7.9(2.7)$ & $<.001$ & $7.9(2.6)$ & $7.7(2.9)$ & .636 \\
\hline
\end{tabular}

lower scores for children tested with the story B from QDR onward.

For the within-subject effects, Mauchly's test of sphericity was significant, $X^{2}{ }_{(20)}=272, p<.001$ and degrees of freedom were again corrected using Greenhouse-Geisser estimates of sphericity $(\varepsilon=0.58)$. An age-dependent effect was seen on the curve described by the trials $\left(F_{(3,5,558)}=7.6, p<.001, \eta_{\mathrm{p}}^{2}=\right.$ $0.08)$. Reanalysis with the older versus younger children showed that the curve could be best described as quadratic $\left(F_{(1,93)}=24.0, p<.001, \eta_{\mathrm{p}}^{2}=0.21\right)$, although a linear $\left(F_{(1,93)}=11.4, p=.001, \eta_{\mathrm{p}}^{2}=0.11\right)$, and cubic curve $\left(F_{(1,93)}=10.6, p=.002, \eta_{\mathrm{p}}^{2}=0.10\right)$ were also significant. The largest age-dependent increase was seen between Q1 and Q2 $\left(F_{(1,93)}=13.5, p<.001, \eta_{\mathrm{p}}^{2}=0.13\right)$; the reanalysis for the older versus younger children showed a larger increase from Q1 to Q2 particularly in the older children. Inclusion of FS-IQ as a covariate did not change the results. A main effect on level of performance was seen for IQ $\left(F_{(1,92)}=6.4\right.$, $\left.p=.013, \eta_{\mathrm{p}}^{2}=0.06\right)$, with a significant effect only at $\mathrm{Q} 1(p$ $<, 001)$ and Q2 $(p=.047)$. There were no main effects of IQ or change $(p=.688)$.

\section{Typically Developing Children Versus Children with Epilepsy}

Free Recall Initial Free Recall, Delayed Free Recalls at day 1 (F.DR Day 1) and the Last trial (F.DR Last Day, either day 2 or day 7; see Table 4 and Fig. 3)

Between-group effects on level of performance on the standardised scores, with alpha set at 0.013 , showed no 
Table 4 Results of repeated measures ANOVA for the Free Recall and the Questions

\begin{tabular}{|c|c|c|c|c|c|c|c|c|c|c|}
\hline & $\mathrm{F}$ & $p$ & $\eta_{\mathrm{p}}^{2}$ & Trials & Meaning & $\mathrm{F}$ & $p$ & $\eta_{\mathrm{p}}^{2}$ & Trials & Meaning \\
\hline \multicolumn{11}{|c|}{ Free Recall: Initial Free Recall, F.DR Day 1; F.DR Last Day (typically developing $N=126$, children with epilepsy $N=159$ ) } \\
\hline \multicolumn{6}{|c|}{ Between subjects (level) d.f. $=279$} & \multicolumn{4}{|c|}{$\begin{array}{l}\text { Within subjects (change), adjusted d.f. } \\
\quad=558\end{array}$} & \\
\hline Intercept & 109.5 & $<.001$ & 0.3 & & & 2.7 & .076 & 0.01 & & \\
\hline Sex & 4.7 & .031 & 0.02 & & & 0.1 & .903 & $<0.001$ & & \\
\hline Age & 0.8 & .387 & 0.003 & & & 1.7 & .191 & 0.006 & & \\
\hline $\begin{array}{l}\text { Story } \\
\text { version }\end{array}$ & 0.2 & .635 & 0.001 & & & 2.7 & .072 & 0.01 & & \\
\hline $\begin{array}{l}\text { Log } \\
\text { number of } \\
\text { days }\end{array}$ & 0.5 & .497 & 0.002 & & & 15.7 & $<.001$ & 0.05 & $\begin{array}{l}\text { DR Day 1-DR last } \\
\text { Day }\end{array}$ & $\begin{array}{l}\text { Longer interval } \\
\text { more loss }\end{array}$ \\
\hline $\begin{array}{l}\text { TD versus } \\
\text { epilepsy }\end{array}$ & 4.5 & .034 & 0.02 & {$[$ Last trial $p<.001]$} & TD > epilepsy & 9.0 & $<.001$ & 0.03 & $\begin{array}{l}\text { DR Day 1-DR last } \\
\text { Day }\end{array}$ & $\begin{array}{l}\text { Epilepsy } \\
\text { more loss }\end{array}$ \\
\hline \multicolumn{6}{|c|}{$\begin{array}{l}\text { Between subjects (level), with IQ, } \\
\text { d.f. }=278\end{array}$} & \multicolumn{5}{|c|}{$\begin{array}{l}\text { Within subjects (change), with IQ, adjusted } \\
\text { d.f. }=556\end{array}$} \\
\hline Intercept & 7.9 & .005 & 0.03 & & & 2.4 & .096 & 0.01 & & \\
\hline Sex & 2.8 & .093 & 0.01 & & & 0.1 & .851 & $<0.001$ & & \\
\hline Age & 0.8 & .359 & 0.003 & & & 1.7 & .192 & 0.006 & & \\
\hline $\begin{array}{l}\text { Story } \\
\text { version }\end{array}$ & 0.8 & .387 & 0.003 & & & 2.9 & .062 & 0.02 & & \\
\hline $\begin{array}{l}\text { Log } \\
\text { number of } \\
\text { days }\end{array}$ & 0.002 & .969 & $<0.001$ & & & 14.5 & $<.001$ & 0.05 & $\begin{array}{l}\text { DR Day 1-DR last } \\
\text { Day }\end{array}$ & $\begin{array}{l}\text { Longer interval } \\
\text { more loss }\end{array}$ \\
\hline FS-IQ & 26.5 & $<.001$ & 0.9 & $\begin{array}{l}\text { Initial, DR Day 1; } \\
\text { DR Last Day }\end{array}$ & High IQ > low IQ & 0.7 & .480 & 0.003 & & \\
\hline $\begin{array}{l}\text { TD versus } \\
\text { epilepsy }\end{array}$ & 0.8 & .379 & 0.003 & & & 9.7 & $<.001$ & 0.03 & $\begin{array}{l}\text { DR Day 1-DR Last } \\
\text { Day }\end{array}$ & $\begin{array}{l}\text { Epilepsy } \\
\text { more loss }\end{array}$ \\
\hline \multicolumn{11}{|c|}{ Questions Q1, Q2, Q3 and Q4 Day 1, Q.DR Day 1 and Q.DR Last Day (typically developing $N=126$, children with epilepsy $N=159$ ) } \\
\hline \multicolumn{6}{|c|}{ Between subjects (level), d.f. $=279$} & \multicolumn{4}{|c|}{$\begin{array}{l}\text { Within subjects (change), adjusted } \\
\text { d.f. }=1395\end{array}$} & \\
\hline Intercept & 58.3 & $<.001$ & 0.2 & & & 1.8 & .129 & 0.01 & & \\
\hline Sex & 3.6 & .057 & 0.91 & & & 0.5 & .731 & 0.002 & & \\
\hline Age & 0.01 & .938 & $<0.001$ & & & 2.2 & .057 & 0.01 & & \\
\hline $\begin{array}{l}\text { Story } \\
\text { version }\end{array}$ & 0.9 & .357 & 0.003 & & & 0.1 & .986 & $<0.001$ & & \\
\hline $\begin{array}{l}\text { Log } \\
\text { number of } \\
\text { days }\end{array}$ & 1.9 & .168 & 0.01 & & & 3.2 & .012 & 0.01 & $\begin{array}{l}\text { Q1-Q2; DR Day } \\
\text { 1-QDR Last }\end{array}$ & $\begin{array}{l}\text { Longer interval } \\
\text { more loss }\end{array}$ \\
\hline $\begin{array}{l}\text { TD versus } \\
\text { epilepsy }\end{array}$ & 10.1 & .002 & 0.04 & $\begin{array}{l}\text { Q3; Q4; QDR Day 1; } \\
\text { QDR Last }\end{array}$ & TD > epilepsy & 3.9 & .003 & 0.01 & Q2-Q3 & $\begin{array}{l}\text { Epilepsy } \\
\text { less gain }\end{array}$ \\
\hline \multicolumn{6}{|c|}{$\begin{array}{l}\text { Between subjects (level), with IQ } \\
\text { d.f. }=278\end{array}$} & \multicolumn{4}{|c|}{$\begin{array}{l}\text { Within subjects (change), with IQ, adjusted } \\
\text { d.f. }=1390\end{array}$} & \\
\hline Intercept & 1.8 & .183 & 0.01 & & & 1.5 & .186 & 0.01 & & \\
\hline Sex & 1.7 & .199 & 0.006 & & & 0.6 & .705 & 0.002 & & \\
\hline Age & 0.006 & .936 & $<0.001$ & & & 2.2 & .058 & 0.01 & & \\
\hline $\begin{array}{l}\text { Story } \\
\text { version }\end{array}$ & 2.1 & .151 & 0.01 & & & 0.1 & .989 & $<0.001$ & & \\
\hline $\begin{array}{l}\text { Log } \\
\text { number of } \\
\text { days }\end{array}$ & 0.4 & .518 & 0.002 & & & 2.9 & .018 & $<0.001$ & $\begin{array}{l}\text { Q2-Q3; DR Day } \\
\text { 1-QDR Last }\end{array}$ & $\begin{array}{l}\text { Longer interval } \\
\text { more loss }\end{array}$ \\
\hline FS-IQ & 41.3 & $<.001$ & 0.13 & All trials & Higher IQ > lower IQ & 0.6 & .656 & 0.002 & & \\
\hline $\begin{array}{l}\text { TD versus } \\
\text { epilepsy }\end{array}$ & 3.0 & .086 & 0.01 & [Q3; Q4; QDR last] & TD > epilepsy & 3.6 & .005 & 0.01 & Q2-Q3 & $\begin{array}{l}\text { Epilepsy } \\
\text { less gain }\end{array}$ \\
\hline
\end{tabular}

$T D$ typically developing children. Values in square brackets are conspicuous results on planned contrasts given non-significant main effect

main effects for sex, age, test version, log number of days or group $(p=.034)$. Noticeably, however, the typically developing children outperformed the children with epilepsy at the last trial $(p<.001)$, indicating that whilst the level of performance of typically developing children and children with epilepsy was overall similar during the first trials, children with epilepsy scored lower at the last trial. Inclusion of FS-IQ showed that whilst effects of IQ were seen on level of performance at all trials $(p s<.001)$; overall, the results remained unchanged.

Within-subject analyses to establish changes across trials (gains or losses), preceded by Mauchly's test of sphericity, 


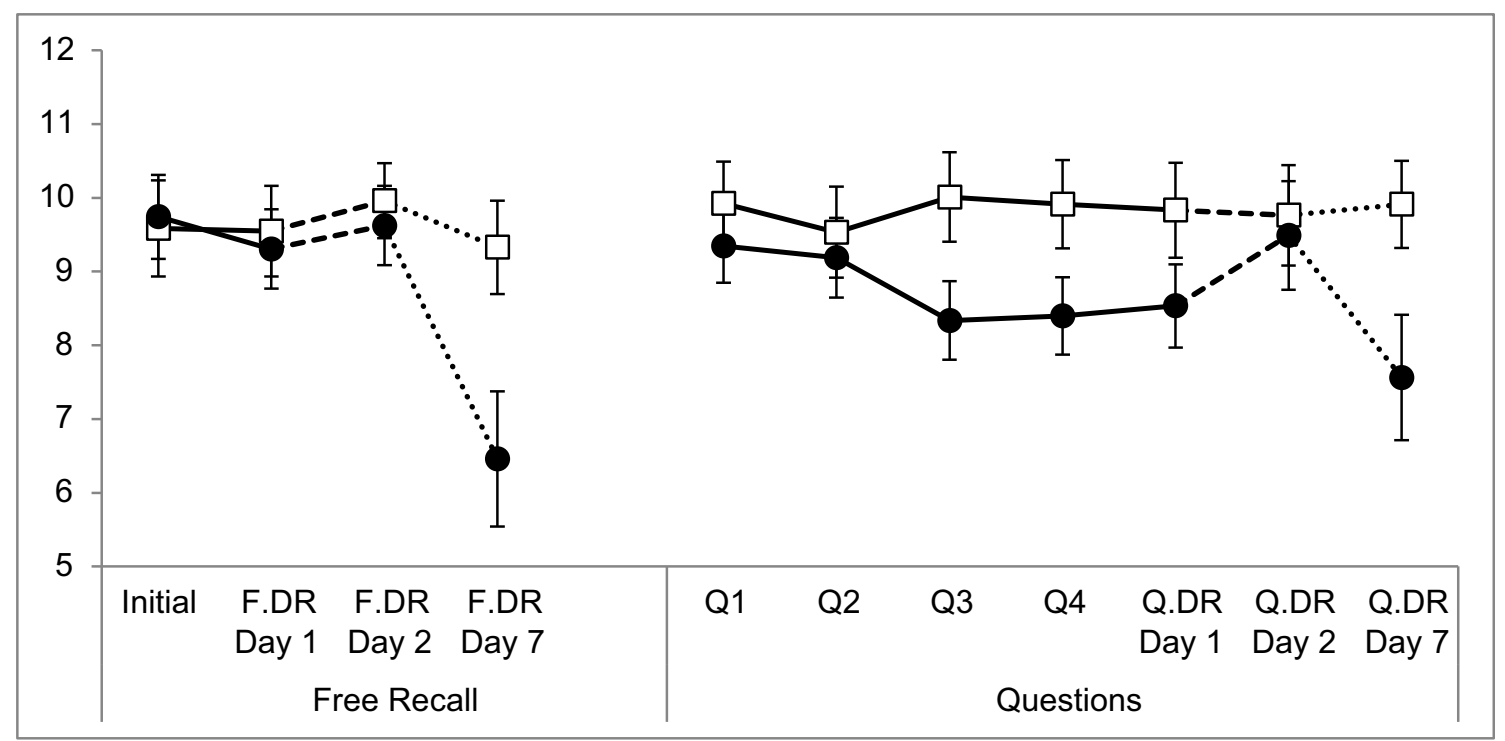

Fig. 3 Free Recall (left) and Questions (right). Estimated standardised means and 95\% confidence intervals. Typically developing children (white squares), and the children with epilepsy (black circles). Based on $n=285$ children on day $1, n=233$ on day 2 , and $n=148$ on day 7 .
Dashed lines indicate that samples sizes differed, and recall scores were estimated as percentage of change. Adjusted for age, sex, story version and log number of days. The $y$-axis denotes the mean standardised score of points earned, mean $=10$ and $\mathrm{SD}=3$, range $1-19$ showed significant main effects for log number of days and group. No significant effects were seen for sex or test version.

Repeated contrasts showed effects of number of days for the time interval F.DR Day 1-F.DR. Last Day $(p<.001)$, indicating that an increased number of days up to the last free recall was associated with more decline of information. This decline was particularly seen in the children with epilepsy $(p<.001)$. Inclusion of FS-IQ indicated that changes across trials were not affected by differences in IQ.

When the analyses were redone up to day 2 (Initial Free Recall, Delayed Free Recall [F.DR Day 1] and Free Recall Day 2 [F.DR Day 2]), no significant effects emerged in level of performance or level of change. No differences were seen between typically developing children and children with epilepsy. When the analyses were redone for the children tested up to day 7 (F.DR Day 7), the results were overall similar to those up to the F.DR. Last Day. Again, main group differences were not clearly seen $\left(F_{(1,143)}=4,1, p=.045, \eta_{\mathrm{p}}^{2}=0.03\right)$, but the typically developing children outperformed the children with epilepsy at day $7(p<.001)$. Changes between trials showed within-group effects $\left(F_{(1.8,286)}=17.1\right.$, $\left.p<.001, \eta_{\mathrm{p}}^{2}=0.11\right)$. Importantly, from F.DR Day 1 to F.DR Day 7 , information declined in children with epilepsy $(p<.001)$, whilst the typically developing children maintained their level. Again, level of performance depended on IQ, but gains or losses were independent of IQ. Figure 3 depicts the marked decline of information in children with epilepsy on Day 7.
Questions Q1 to Q4, Delayed Recalls of Questions the same day (Q.DR Day 1), and up to the last trial (Q.DR Last Day, either Q.DR Day 2 or Q.DR Day 7) (See Table 4 and Fig. 3.)

No differences on level of performance as reflected by the between-subject effects were significant for sex, age, story version or log number of days.

The level of performance on the questions, however, differed depending on group. These differences emerged from Q3 onward (Fig. 3) At Q1 ( $p=.143)$ and Q2 ( $p=.447)$, no differences were seen between the groups; thereafter, typically developing children outperformed the children with epilepsy (Q3, $p<.001 ; \mathrm{Q} 4, p=.001$; Q.DR Day $1, p=.008$; Q.DR Last Day, $p<.001$ ). When FS-IQ was included in the analysis, effects of IQ $(p s<.001)$ were seen on all trials. Group differences were less pronounced, but were still seen for Q3, Q4 and QDR Day 1, suggesting that the diverging learning curve seen in children with epilepsy was seen independent of differences in IQ.

Main within-subject effects were seen for log number of days and group. Repeated contrasts showed the effects of log number of days for the changes between Q1 and Q2 ( $p=.044$, more gains were seen in the subset of children retested at day 7) and between Q.DR Day 1 and Q.DR Last Day ( $p=.001$, suggesting that with a longer time interval, the amount of information declined). Interestingly, a differential effect for group was seen between Q2 and Q3, $F_{(1,279)}=15.2$, $p<.001, \eta_{\mathrm{p}}^{2}=.05$, indicating less gains in the children with epilepsy relative to the typically developing children. Inclusion of FS-IQ showed that level of performance was affected by IQ on all trials, but did not affect gains or losses. 
The significant Q2-Q3 value for group was no longer seen $(p=.069)$. Typically developing children outperformed children with epilepsy on all trials from Q3 onward. No effects of participation in the KEC programme were seen.

The analyses were redone separately for the trials at day 1 up to day 2, as well as for day 1 to day 7 , yielding overall similar results. The analyses for day 1 and day 2 showed a similar deviating curve from Q3 onward (differences between level of performance) but did no longer reveal significant main effects for change $(p=.067)$. The analyses for day 1 and day 7 revealed an additional effect of age, $F_{(4.1,715)}=2,4, p=.046$, $\eta_{\mathrm{p}}^{2}=0.02$, with significant effects on learning at Q2-Q3 (younger children grew slower than older children), and retention Q.DR Day 1-Q.DR Day 7 (younger children retained the information better).

\section{Reliable Cognitive Change}

Age-adjusted standard scores were combined to index scores according to the test manual. The index scores are composite measures for the standardised Free Recall and the Questions. For the Learning Index, the standardised score of for the questions is based on the sum of Q1 to Q4. Differences and rates of children showing changes in performance within and beyond the $90 \%$ confidence intervals based on cut-offs from the manual were established between (1) the Learning Index and the Delayed Recall Index at Day 1; (2) Delayed Recall Index at
Day 1 and Delayed Recall Index at Day 2; and (3) Delayed Recall Index at Day 1 and Delayed Recall Index at Day 7.

Means and standard deviations of the index scores are shown in Table 3. Independent samples $t$ tests showed that the mean change of index scores between the Learning Index and Recall Index at Day 1 were similar for both groups $\left(t_{(279,1)}=0.36, p=.719\right)$ and between day 1 and day 2 $\left(t_{(189,1)}=0.36, p=.718\right)$. In line with the earlier results, between day 1 and day 7, a larger decline for the children with epilepsy was seen $\left(t_{(69,1)}=-5.35, p<.001\right)$.

Rates of children remaining stable or showing reliable gains or losses beyond the cut-off scores were different between groups. Chi-square at day $1\left(X_{(285,2)}^{2}=12.6, p=.002\right)$ showed that the sample of children with epilepsy contained more children showing reliable changes, seen as gains $(8.2 \%)$ and losses $(6.3 \%)$ relative to the typically developing children $(0.8 \%$ had gains, $1.6 \%$ losses). Between Delayed Recall Index Day 1 and Day 2, values were similar across groups $\left(X_{(233,2)}^{2}=5.8\right.$, $p=.055)$. Notably, $12.7 \%$ of the children with epilepsy and $7.3 \%$ of typically developing children had made significant gains between days 1 and 2. For losses, values were $7.3 \%$ for epilepsy and $3.3 \%$ for the typically developing children. Changes between the Delayed Recall Index Day 1 and Delayed Recall Index Day 7 showed elevated rates of loss in children with epilepsy $\left(X_{(148,2)}^{2}=23.2, p<.001\right)$. Gains were seen in none of the children with epilepsy $(0.0 \%)$ and $2.0 \%$ of typically developing children. There was a conspicuously high

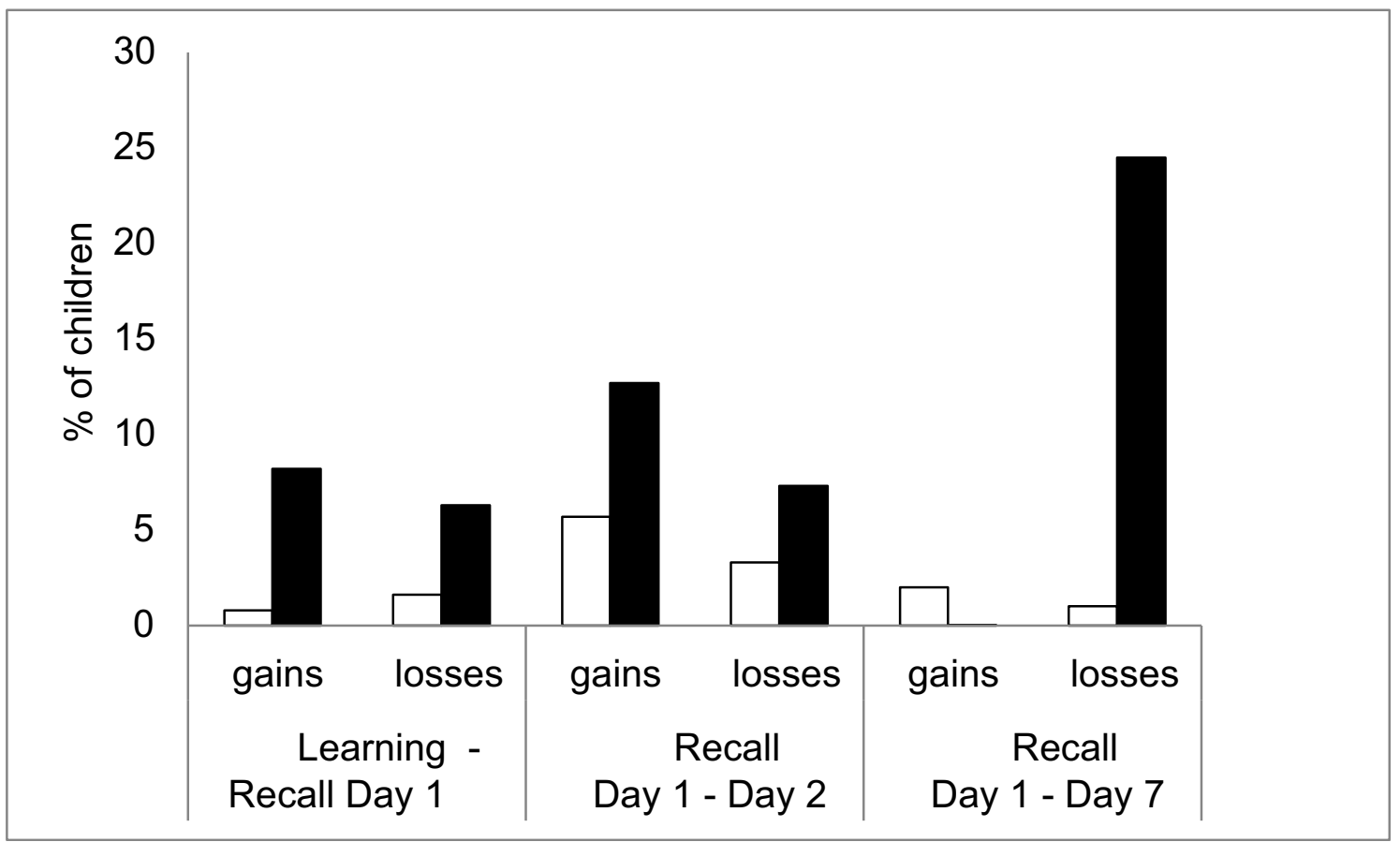

Fig. 4 Reliable cognitive change of index scores. Rates of typically developing children (white) and children with epilepsy (black) showing reliable gains and losses over time. Within day 1 , from Learning Trials to
Delayed Recall (90\% C.I. cut-off value 23), Delayed Recall between day 1 and day 2 (cut-off 17) and between day 1 and day 7 (cut-off 18) 
rate $(24.5 \%)$ of children with epilepsy showing memory loss at day 7 , not seen in typically developing children (1.0\%). Rates of children showing reliable gains and losses are shown in Fig. 4.

\section{Neuropsychological Variables}

Based on the complete sample, the impact of neuropsychological test variables on the Learning Index, the Delayed Recall Indexes Day 1 and the Last Day (dependent variables) was analysed doing repeated measures ANOVA with repeated contrasts. Standardised values for Vocabulary, Lindeboom rapid confrontational naming (Lamberink et al. 2018), Fluency for Animals and Verbs (combined measure), Digit Span Forwards and Digit Span Backwards were entered as independent variables. Data were adjusted for age, sex, story version and log number of days and alpha was set at 0.005 .

Significant main between-subject effects were seen for Vocabulary $\left(F_{(1,274)}=16.0, p<.001, \eta_{\mathrm{p}}^{2}=0.06\right)$, Lindeboom $\left(F_{(1,274)}=13.4, p<.001, \eta_{\mathrm{p}}^{2}=0.05\right)$, Fluency for animals and verbs $\left(F_{(1,274)}=8.4, p=.004, \eta_{\mathrm{p}}^{2}=0.03\right)$, and Digit Span Backwards $\left(F_{(1,274)}=7.7, p=.006, \eta_{\mathrm{p}}^{2}=0.03\right)$. For Lindeboom, Fluency and Digit Span Backwards, higher scores were associated with higher index scores at all measurement points; for Vocabulary, at Day 1 but no longer at the Last Day. For changes over time, after adjusting the degrees of freedom in line with Greehouse-Geisser, no significant main within-subject effects for neuropsychological variables.

\section{Epilepsy Variables}

The results of general linear models are presented in Table 5 for the base and final model. Comparisons of the Aikaike's information criteria (AICs) between the base and later models showed improvements on models containing measures of severity and duration of epilepsy. Model 2, which included variables on seizure type, localisation or lateralisation of epilepsy, showed no improvement relative to the base model on any index score. The base model was improved for all index scores in model 3, which included measures on severity. Abnormalities on the MRI $(p=.018)$ and active epilepsy $(p=.028)$ were associated with lower scores on the Learning Index; a history of status epilepticus, SE $(p=.073$ DR Day 1 ; $p=.045$ DR Last Day) and active epilepsy ( $p=.092$ DR Day $1 ; p=.032$ DR Last Day) were associated with lower scores on Delayed Recall Indexes at day 1 and the last day. Model 4, which included the time-related variables age at onset of epilepsy and duration of epilepsy up to testing, also was improved relative to the base model on the Learning Index and the Delayed Recall Index at day 1, whilst AIC for Delayed Recall at day 7 remained equal. Longer duration of epilepsy was associated with lower scores at all trials $(p=.065$ Learning Index; $p=.026$ Delayed Recall Index Day 1; $p=.020$ Delayed Recall Index Last Day).

The final model comprised the variables of the base model, together with MRI+, SE, inactive epilepsy and duration of epilepsy (Table 5). The final model suggested that girls

Table 5 Results of base and final models for generalised linear models for the index scores, with epilepsy variables

iter-SEIN Index scores

\begin{tabular}{|c|c|c|c|c|c|c|c|c|c|c|c|c|}
\hline & \multicolumn{4}{|c|}{ Learning Index } & \multicolumn{4}{|c|}{ Delayed Recall Index Day 1} & \multicolumn{4}{|c|}{ Delayed Recall Index Last Day } \\
\hline & $\beta$ & S.E. & $p$ & $95 \%$ C.I & $\beta$ & S.E. & $p$ & $95 \%$ C.I & $\beta$ & S.E. & $p$ & $95 \%$ C.I \\
\hline \multicolumn{13}{|l|}{ Base model } \\
\hline Sex (boy) & -5.58 & 2.9 & .058 & $-11.3 ; 0.2$ & -6.40 & 2.8 & .023 & $-11.9 ;-0.9$ & -3.91 & 2.7 & .152 & $-9,3 ; 1.4$ \\
\hline Age (years) & -0.81 & 0.9 & .387 & $-2.6 ; 1.0$ & -1.28 & 0.9 & .151 & $-3.0 ; 0.5$ & -1.66 & 0.9 & .056 & $-3.4 ; 0.04$ \\
\hline Log days & & & & & & & & & -10.86 & 5.9 & .059 & $-22.1 ; 0.4$ \\
\hline Deviance & $51,708.9$ & & & & $47,610.2$ & & & & $44,098.7$ & & & \\
\hline AIC & 1356.1 & & & & 1343.2 & & & & 1325.7 & & & \\
\hline \multicolumn{13}{|l|}{ Final model } \\
\hline Sex (boy) & -6.14 & 2.8 & .027 & $-11.6 ;-0.7$ & -6.98 & 2.7 & .009 & $-12.2 ;-1.7$ & -4.04 & 2.6 & .122 & $-9.2 ; 1.1$ \\
\hline Status epilepticus & -4.42 & 4.8 & .360 & $-13.9 ; 5.1$ & -8.47 & 4.7 & .069 & $-17.6 ; 0.7$ & -9.22 & 4.6 & .043 & $-18.2 ;-0.3$ \\
\hline MRI+ & -9.73 & 4.8 & .041 & $-19.3 ;-0.4$ & -5.47 & 4.6 & .323 & $-14.5 ; 3.5$ & -7.44 & 4.5 & .079 & $-16.2 ; 1.3$ \\
\hline Inactive epilepsy & 9.28 & 3.7 & .013 & $2.0 ; 16.6$ & 7.85 & 3.6 & .029 & $0.8 ; 14.9$ & 8.10 & 3.5 & .021 & $1.2 ; 15.0$ \\
\hline Duration of epilepsy & -0.15 & 0.1 & .005 & $-0.2 ;-0.05$ & -0.15 & 0.1 & .002 & $-0.3 ;-0.05$ & -0.11 & 0.05 & .026 & $-0.2 ;-0.01$ \\
\hline Log days & & & & & & & & & -10.83 & 5.6 & .051 & $-21.7 ; 0.1$ \\
\hline Deviance & $45,656.5$ & & & & $42,386.4$ & & & & $40,362.0$ & & & \\
\hline AIC & 1335.1 & & & & 1323.6 & & & & 1318.0 & & & \\
\hline
\end{tabular}

S.E. standard error, Log days log (10) number of days up to last test, $M R I+$ MRI findings on neuroimaging (versus no MRI done or negative findings), Inactive epilepsy no seizures in past 12 months, AIC Aikaike's information criterion 
outperformed boys during the Learning and Retention Day 1, but no longer the last day. The presence of status epilepticus in the child's history was increasingly associated with lower scores as the testing trials progressed; the presence of MRI abnormalities was associated with lower scores on the Learning Index; active epilepsy was associated with lower scores on the iter-SEIN on all index scores. Longer duration of epilepsy was also associated with lower scores on all index scores. As seen earlier, a longer time interval up to the last trial was associated with lower scores at Delayed Recall Index of the Last Day. It should be noted, however, that SE and MRI+ each affected less than $10 \%$ of the children in the present sample, and that effect sizes of all significant epilepsy variables were small.

Separate analyses for Delayed Recall Indexes on the subset tested at day 2 showed that none of the epilepsy variables improved the base model. Only the final model appeared as an improved model, with duration of epilepsy as only significant variable $(p=.034)$. The Fourth Model for Delayed Recall Index Day 7 showed a significant contribution of MRI $(p=.036)$ and active epilepsy $(p=.018)$, which were no longer significant in the final model. No significant values emerged for duration of epilepsy for the subset tested at day 7 .

Finally, an analogous procedure was followed entering the measures of change based on the differences between the index scores (Learning Index-Delayed Recall Index Day 1; Delayed Recall Index Day 1-Delayed Recall Index last Day). The Base Model for the difference between Learning Index and Delayed Recall Index Day 1 was improved only by model 2, with a significant value for frontal lobe involvement of seizures $(p=.003)$. The final model with frontal lobe involvement only $(p=.001)$ was also an improved model. Similarly, the base model for the difference between Delayed Recall Index Day 1 and Delayed Recall Index Last Day (which also included log number of days) was improved in the final model containing frontal lobe involvement $(p=.020)$. Noticeably, frontal lobe involvement of seizures was associated with larger gains at day 1 , and with larger losses between day 1 and last day.

\section{Discussion}

The present study aimed at describing the curve of learning and remembering of verbal declarative information in typically developing children and children with epilepsy on a task with both semantic and episodic components, assumed to have high ecological validity for verbal learning in the school setting. Earlier epilepsy studies had found memory deficits in selected children with epilepsy. With some important exceptions, children were generally tested on the first day only. The present study differed from earlier studies in several ways: (1) it reported on a heterogeneous group of children who presented in a clinical epilepsy setting, (2) with lateconsolidation measures of a story as part of standard clinical neuropsychological assessment, (3) based on a story telling test specifically developed to tap story learning and recall in children also beyond day 1, at day 2 and up to day 7 .

The analyses on the typically developing children validated the iter-SEIN as a developmental test, with age-dependent increases in level of performance. The learning paradigm including repeated presentations showed that for the free recall, information learned in the first trial, was overall maintained up to day 7. The questions showed a quadratic learning curve, with increasing numbers of questions answered across learning trials; thereafter, information was largely retained over time.

Different curves emerged for children with epilepsy compared with typically developing children, providing evidence for decelerated learning and accelerated forgetting in children with epilepsy. Twenty four percent of the children with epilepsy showed reliable cognitive loss of the information after 1 week.

Level of performance, but not ability to learn across trials, was associated with verbal neuropsychological abilities like vocabulary, fluency, naming and working memory. Beyond the epileptic condition itself, the time-related variable duration of epilepsy and some severity measures emerged that were associated with level of performance.

\section{The Age-Related Learning Trajectory for Typically Developing Children}

The analyses suggested that the iter-SEIN taps development of declarative memory in children between ages 4 and 10 years: level of performance on the iter-SEIN was dependent on the age of the child: with increasing age, children were able to provide more fragments contained in the story and provide more answers to the set of questions.

Age-related improvements, somewhat differing between the younger and older children and overall suggesting larger gains in the older children during the first day, reflected the rapid changes over time taking place in children in the ages between 4 and 10 years in story learning. Episodic memory relies on distributed networks in the brain, and age-related improvements are thought to be associated with increased specialisation and concerted action of various brain areas, particularly the hippocampus, the prefrontal cortex and the parietal cortex (see Ghetti and Bunge 2012, for a review).

\section{Differential Trajectories for Typically Developing Children and Children with Epilepsy}

Typically developing children outperformed children with epilepsy increasingly during the course of the assessment trials up to 1 week. Two conspicuous differences were seen when 
the groups were contrasted: (1) children with epilepsy showed a deceleration of learning after the second trial of questions, leading to divergent learning curves at later trials; and (2), on the free recall, children with epilepsy lost more information from the first day to 1 week later, providing evidence for accelerated forgetting. Based on reliable cognitive change scores for the indexes, the group with epilepsy had higher rates of children showing changes (gains or losses) during the first day between the Learning Trials and Delayed Recall. Also, noticeably higher rates of children with epilepsy with reliable losses were seen between the first day and the last day. One out of four children with epilepsy presented with memory loss after 1 week.

Overall, the study suggested that acquisition across trials is reduced in children with epilepsy, early retention and consolidation (Baker and Zeman 2017) is similar to typically developing children, and late consolidation (Baker and Zeman 2017) appears disturbed. Based on a study where young adults were asked to describe the story presented in film clips for a period of 7 days, earlier authors (Sekeres et al. 2016; Sekeres et al. 2017) described that in the course of time, the quality and the context of the film is transformed and reorganised into a broader brain network. Immediately after encoding, memory is highly dependent on the hippocampus. Over the course of 1 week, the core of the film was still present, whilst the details diminished. These changes were accompanied by increased engagement of the medial prefrontal cortex. Detailed descriptions of the content continued to be dependent of the hippocampus.

Studies providing a single presentation of information and a delayed recall after half an hour generally show some loss of information (Davidson et al. 2007; Jambaqué et al. 1993; Rzezak et al. 2012). In the present study, as expected, the effect of repetitions was reflected in overall retention up to the next day, also in children with epilepsy.

In line with the decelerated learning observed in the present study on the questions, reduced learning across trials and an increasing deviation from the curve had been observed earlier on a word list task in children under the age of 10 with benign epilepsy with centro-temporal spikes (Vago et al. 2008). Similarly, a higher number of learning trials to criterion of a story was also reported for children with idiopathic generalised epilepsy (Davidson et al. 2007), suggesting less efficient learning in children with epilepsy. In the present study, the gains made by $12 \%$ of the children with epilepsy a day later may suggest that some children with epilepsy are more prone to experience "learning fatigue" during the learning process and show better performance after a night's rest — even in an epilepsy clinic. An explanation for the overall retention of information at day 2 is provided by Elliott et al. (2014) who stated that studies with repeated presentations, in particular learning-to-criterion paradigms, may be prone to "overlearning" and less likely to show forgetting the next day. This effect may have been more conspicuous for the children with epilepsy, given the larger number of learning trials. In spite of this result, the overall favourable effect was not maintained for a longer period of time in epilepsy.

\section{The Impact of Epilepsy Variables}

An impact of epilepsy variables was seen for the time-related variable duration of epilepsy as well as on some measures of severity. Longer duration of epilepsy, abnormalities on neuroimaging, episodes of status epilepticus in the child's history and active epilepsy were associated with lower scores on the Index scores. Children with frontal lobe involvement of seizure were not hindered to make gains during day 1 ; however, they were prone to lose this advantage after day 1 .

Earlier authors had hypothesised that longer duration of epilepsy could be associated with accelerated long-term forgetting (Gascoigne et al. 2014). In the present study, longer duration of epilepsy was indeed associated with lower scores on all index scores. The detrimental impact of duration of epilepsy on cognitive abilities is in line with earlier results (Menlove and Reilly 2015; van Iterson et al. 2014). Abnormalities on the MRI, with added epilepsy, had been reported earlier to affect cognitive development in children (Ballantyne et al. 2008). Also, a history of status epilepticus has been shown earlier to produce lasting brain changes, particularly in brain areas associated with memory and learning and memory (Lewis et al. 2014; Martinos et al. 2018), or other cognitive functions, especially in the context of epilepsy (Pujar et al. 2018). It should be noted, however, that the number of children representing each epilepsy variables was small; thus, the results should be considered preliminary and awaiting further confirmation.

No epilepsy variable on type of epilepsy, localisation or lateralisation was found to contribute significantly to level of performance. This is in line with earlier studies on cognitive function in children with epilepsy, which showed that specific epilepsy variables are not always found (Braakman et al. 2012; Oostrom et al. 2005; Reijs et al. 2006), or that results are inconsistent. Inconsistent findings have been found for example on the role of left versus right lateralisation of seizures on verbal tasks (Jambaqué et al. 1993; Menlove and Reilly 2015; Szabo et al. 1998).

The present results indicate that the non-optimality of brain development, leading to the epileptic condition, is reflected in the scores as found in children with epilepsy. This was already highlighted by studies on adults indicating that accelerated forgetting is often seen in epilepsy (Helmstaedter et al. 2018) as well as in children indicating that accelerated forgetting is also seen later in the course of the epilepsy (GraysonCollins et al. 2019). The results may also reflect that in the different stages of learning and forgetting, throughout the various trials, different brain areas may be at stake. Earlier authors have proposed that memories are dependent on different brain 
areas at different stages of consolidation. For example, the initial memory formation and early consolidation may rely more on medial temporal lobe, whilst late consolidation is more dependent on the frontal lobes (Sekeres et al. 2017). This explanation would be in line with the present results, suggesting that in the light of frontal lobe involvement of seizures, during day 1 , gains were made, which were lost in the phase of late consolidation.

\section{Neuropsychological Variables}

Following common research tradition, after analysing the data on the story test, IQ was added as covariate in the various analyses. Earlier authors (Dennis et al. 2009) have warned for applying IQ as a covariate in developmental disorders. In the present paper, a higher IQ was helpful in the story learning test. Children with higher Full-Scale IQs had overall higher scores. The deceleration of learning was seen to depend partially on IQ; the decline of scores after a week, observed in children with epilepsy, was seen independent of IQ.

Similarly, children who had higher scores on vocabulary and who were more verbally fluid, as seen in confrontational naming and verbal fluency tasks, and children with better working memory also scored higher on the iter-SEIN on almost all trials. This association with semantic tasks supports the notion that story learning is also a semantic memory task, not only tapping episodic memory (Smith and Lah 2011). However, a word of caution is needed with regard to verbal fluency, given the lack norm scores for the youngest children.

\section{Assets and Weaknesses of the Study}

A weakness in the present study relates to the number of recall trials in the children with epilepsy relative to the typically developing children. These differences arose given that the typically developing children were part of the norm group for the story test and were retested the next day as well as a week later to provide norm data for delays of varying lengths. The clinical sample followed the procedure applied in the clinical setting and was retested either the next day or a week later. Some authors have suggested that repeated recall may have a protective effect against the loss of information and lead to increased retention (Elliott et al. 2014; Ricci et al. 2015; Sekeres et al. 2016). This is in line with authors suggesting that every new reactivation of memory produces a new trace in the mesial temporal lobe and the neocortex, strengthening and consolidating the earlier information (Baker and Zeman 2017; Nadel and Moscovitch 1997).

For example, a positive effect of an additional retrieval session 1 day after presentation was seen on a series of film clips presented to healthy young adults (Sekeres et al. 2016). In terms of the present study, these results may not be readily comparable, given the large number of film clips presented a single time, whilst in the present study, a single story was given repeatedly. The story was presented several times, more often to the children with epilepsy than in typically developing children, therefore possibly strengthening the memory during acquisition (Davidson et al. 2007). Ricci et al. (2019) also found a positive effect of an additional recall session after 2 weeks on story recall a month later. This effect, however, was only seen when no active elaboration of the material was provided during acquisition. When active elaboration of the material was provided - analogous to the learning sessions with questions of in the present study-results were less likely to be influenced significantly by this difference in number of recall sessions. Thus, the reactivation given to the typically developing children may have helped in remembering better over time, but given the larger number of trials in the learning stage for the children with epilepsy, and given the active elaboration of the material, it seems unlikely that the robust effects of accelerated long-term forgetting found in the present study should be attributed solely to this difference in number of retrieval trials. Further studies on the effect of repeated recall after 1 day on remembering a week later would shed better light on this topic. For the moment, it can be safely concluded, that, in the absence of an extra recall trial, but given a larger number of presentations in the learning phase, children with epilepsy are likely to lose information in the course of 1 week.

This being said, the presence of data for day 2 as well as day 7 can be considered a major asset of the present study. The iter-SEIN was developed to fit the need of the clinical child neuropsychologist who wants to provide an answer to the question, frequently heard from neurologists, parents and teachers, whether information is learned properly in the learning phase, and whether it is lost at an accelerated speed thereafter. The present study showed that children with epilepsy learn somewhat slower, retain information adequately up to the next day, but information is likely to decay at an accelerated pace thereafter.

An additional asset of the present work is that, beyond reporting on story memory with short as well as long delays in standardised assessment of children with epilepsy, it also reports on frequencies of significant loss of information based on normative values.

Decelerated learning and accelerated forgetting may well have an impact on the child's general cognitive development. Earlier studies have found that children with epilepsy often show an advantage on the verbal IQ scores in the early stages of the epilepsy, which is lost over time. With increasing duration, during the course of epilepsy, verbal IQ (more clearly so than performance IQ) shows a logarithmic decline (van Iterson et al. 2014). Indeed, when children with epilepsy were retested after a 2-year interval with the same Wechsler scales, one out of four (26\%) children had shown significant cognitive loss on the verbal scale (van Iterson et al. 2013). It is 
conceivable that the decelerated acquisition and the accelerated loss of verbal information as seen in the iter-SEIN — crucial in everyday school life-will reflect itself in the long run in these lowered verbal cognitive scores.

\section{Clinical Implications of the Study}

Understanding the phenomenon of decelerated learning in children with epilepsy may aid teachers, parents and children in programming the learning sessions: repeated learning does have a beneficial effect over time, but this effect decreases when the duration of the sessions becomes longer. Therefore, more frequent, shorter teaching sessions will probably be helpful. The beneficial effect of repetitions will likely last at least up to the next day.

Knowing that a child with epilepsy is more viable to forget learned information over time than a child without epilepsy, and that this concerns particularly the free recall, is the first step for educators and parents to deal with these difficulties. It may aid in understanding and therefore reducing the stress in children, teachers and parents when a situation presents itself like "he knew his lessons perfectly last week, but now it is all gone", or "I did learn to get a high score, and yet I failed the school exam". Such may indeed occur in any child with epilepsy. In-depth elaboration of the material, as in repeated trials, being questioned by parents, discussion of the learned material, may help; renewed learning in the days between the first learning and the exam may be imperative. Also, applying structured cues as in questions may more likely bring to the light what the child has retained, rather than an open request to provide the information remembered.

The finding that children with epilepsy generally maintain their level of knowledge at day 1 and up to the next day should alert the clinical neuropsychologist whenever a child forgets the information already the first day or the next day. This kind of forgetting is unusual, also in a child with epilepsy, and could be pointing to more serious deficits with retention of information.

Acknowledgements The author would like to thank Roos Rodenburg from the University of Amsterdam, and all students and testing assistants who aided in the collection of the data. The author thanks Alan S. Kaufman from Yale School of Medicine and test developer par excellence for his encouragement and his valuable comments on the draft.

Compliance with Ethical Standards The study is an observational study. In accordance with ethical standards, informed consent was obtained from the parents. Data on normal children were collected by students; data on children with epilepsy were collected in the regular clinical setting.

Open Access This article is distributed under the terms of the Creative Commons Attribution 4.0 International License (http:// creativecommons.org/licenses/by/4.0/), which permits unrestricted use, distribution, and reproduction in any medium, provided you give appropriate credit to the original author(s) and the source, provide a link to the Creative Commons license, and indicate if changes were made.

\section{References}

Baker, J., \& Zeman, A. (2017). Accelerated long-term forgetting in epilepsy - and beyond. In N. Axmacher \& B. Ratsch (Eds.), Cognitive neuroscience of memory consolidation (pp. 401-417). Cham: Springer.

Ballantyne, A. O., Spilkin, A. M., Hesselink, J., \& Trauner, D. A. (2008). Plasticity in the developing brain: Intellectual, language and academic functions in children with ischaemic perinatal stroke. Brain, 131(Pt 11), 2975-2985.

Braakman, H. M., Ijff, D. M., Vaessen, M. J., Debeij-van Hall, M. H., Hofman, P. A., Backes, W. H., ... Aldenkamp, A. P. (2012). Cognitive and behavioural findings in children with frontal lobe epilepsy. European Journal Paediatric Neurology, 16(6), 707-715.

Broekhuis, J. B. C. (2006). Een vernieuwende verbale geheugentest voor 6 tot en met 10-jarige kinderen en hun verbale geheugenontwikkeling. (masters), Universiteit Utrecht, Utrecht.

Cormack, F., Vargha-Khadem, F., Wood, S. J., Cross, J. H., \& Baldeweg, T. (2012). Memory in paediatric temporal lobe epilepsy: effects of lesion type and side. Epilepsy Research, 98(2-3), 255-259. https:// doi.org/10.1016/j.eplepsyres.2011.09.004.

Davidson, R. J., Dorris, L., O’Regan, M., \& Zuberi, S. M. (2007). Memory consolidation and accelerated forgetting in children with idiopathic generalized epilepsy. Epilepsy and Behavior, 11, 394400 .

Dennis, M., Francis, D. J., Cirino, P. T., Schachar, R., Barnes, M. A., \& Fletcher, J. M. (2009). Why IQ is not a covariate in cognitive studies of neurodevelopmental disorders. Journal of the International Neuropsychological Society, 15(3), 331-343. https://doi.org/10. 1017/S1355617709090481.

Dunn, D. W., Buelow, J. M., Austin, J. K., Shinnar, S., \& Perkins, S. M. (2004). Development of syndrome severity scores for pediatric epilepsy. Epilepsia, 45(6), 661-666

Elliott, G., Isaac, C. L., \& Muhlert, N. (2014). Measuring forgetting: a critical review of accelerated long-term forgetting studies. Cortex, 54, 16-32. https://doi.org/10.1016/j.cortex.2014.02.001.

Frisk, V., \& Milner, B. (1990). The role of the left hippocampal region in the acquisition and retention of story content. Neuropsychologia, 28, 349-359.

Garson, G. D. (2012). Generalized linear models and generalized estimating equations. Statistica Associates Blue Book Series. Hierarchical Linear Modeling, Statistical Publishing Associates, Asheboro (pp. 350).

Gascoigne, M. B., Barton, B., Webster, R., Gill, D., Antony, J., \& Lah, S. S. (2012). Accelerated long-term forgetting in children with idiopathic generalized epilepsy. Epilepsia, 53(12), 2135-2140. https:// doi.org/10.1111/j.1528-1167.2012.03719.x.

Gascoigne, M. B., Smith, M. L., Barton, B., Webster, R., Gill, D., \& Lah, S. (2014). Accelerated long-term forgetting in children with temporal lobe epilepsy. Neuropsychologia, 59, 93-102. https://doi.org/10. 1016/j.neuropsychologia.2014.04.012.

Ghetti, S., \& Bunge, S. A. (2012). Neural changes underlying the development of episodic memory during middle childhood. Developmental Cognitive Neuroscience, 2(4), 381-395. https://doi. org/10.1016/j.den.2012.05.002.

Grayson-Collins, J., Gascoigne, M. B., Barton, B., Webster, R., Gill, D., \& Lah, S. (2019). Longitudinal study of accelerated long-term forgetting in children with genetic generalized epilepsy: evidence of ongoing deficits. Cortex. 
Helmstaedter, C., Winter, B., Melzer, N., Lohmann, H., \& Witt, J. A. (2018). Accelerated long-term forgetting in focal epilepsies with special consideration given to patients with diagnosed and suspected limbic encephalitis. Cortex. https://doi.org/10.1016/j.cortex.2018. 01.003.

Jambaqué, I., Dellatolas, G., Dulac, O., Ponsott, G., \& Signoret, J. L. (1993). Verbal and visual memory impairment in children with epilepsy. Neuropsychologia, 31(12), 1321-1337.

Jambaqué, I., Dellatolas, G., Fohlen, M., Bulteau, C., Watier, L., Dorfmuller, G., ... Delalande, O. (2007). Memory functions following surgery for temporal lobe epilepsy in children. Neuropsychologia, 45, 2850-2862.

Jambaqué, I., Pinabiaux, C., Dubouch, C., Fohlen, M., Bulteau, C., \& Delalande, O. (2009). Verbal emotional memory in children and adolescents with temporal lobe epilepsy: a first study. Epilepsy and Behavior, 16, 69-75.

Jocic-Jakubi, B., \& Nebojsa, J. J. (2006). Verbal memory impairment in children with focal epilepsy. Epilepsy and Behavior, 9, 432-439.

Korkman, M., Kirk, U., \& Kemp, S. (2010). NEPSY-II-NL. Afnamehandleiding. Test Manual. Amsterdam, Pearson.

Lah, S., \& Smith, M. L. (2014). Semantic and episodic memory in children with temporal lobe epilepsy: do they relate to literacy skills? Neuropsychology, 28(1), 113-122. https://doi.org/10.1037/ neu0000029.

Lamberink, H. J., Boshuisen, K., Otte, W. M., Geleijns, K., Braun, K. P., Group, T. S, et al. (2018). Individualized prediction of seizure relapse and outcomes following antiepileptic drug withdrawal after pediatric epilepsy surgery. Epilepsia, 59(3), e28-e33.

Lewis, D. V., Shinnar, S., Hesdorffer, D. C., Bagiella, E., Bello, J. A., Chan, S., ... Team, F. S. (2014). Hippocampal sclerosis after febrile status epilepticus: the FEBSTAT study. Annals of Neurology, 75(2), 178-185. doi:https://doi.org/10.1002/ana.24081.

Lezak, M., Howieson, D. B., \& Loring, D. W. (2004). Neuropsychological assessment (4th ed.). Oxford: Oxford University Press.

Lopes, A. F., Monteiro, J. P., Fonseca, M. J., Robalo, C., \& Simões, M. R. (2014). Memory functioning in children with epilepsy: frontal lobe epilepsy, childhood absence epilepsy, and benign epilepsy with centrotemporal spikes. Behavioural Neurology, 2014, 218637.

Lou Smith, M., Elliott, I. M., \& Lach, L. (2006). Memory outcome after pediatric epilepsy surgery: objective and subjective perspectives. Child Neuropsychology, 12(3), 151-164. https://doi.org/10.1080/ 09297040591001076.

Martinos, M. M., Pujar, S., Gillberg, C., Cortina-Borja, M., Neville, B. G. R., De Haan, M., ... Chin, R. F. M. (2018). Long-term behavioural outcomes after paediatric convulsive status epilepticus: a population-based cohort study. Developmental Medicine and Child Neurology, 60(4), 409-416. doi:https://doi.org/10.1111/dmcn. 13636.

Menlove, L., \& Reilly, C. (2015). Memory in children with epilepsy: a systematic review. Seizure, 25, 126-135. https://doi.org/10.1016/j. seizure.2014.10.002.

Morris, J., Kunka, J. M., \& Rossini, E. D. (1997). Development of alternate paragraphs for the Logical Memory subtest of the Wechsler Memory Scale-Revised. The Clinical Neuropsychologist, 11(4), 370-374.

Murre, J. M., \& Dros, J. (2015). Replication and analysis of Ebbinghaus' forgetting curve. PLoS One, 10(7), e0120644. https://doi.org/10. 1371/journal.pone.0120644.

Nadel, L., \& Moscovitch, M. (1997). Memory consolidation, retrograde amnesia and the hippocampal complex. Current Opinion in Neurobiology, 7(2), 217-227.

Northcott, E., Connolly, A. M., Berroya, A., McIntyre, J., Christie, J., Taylor, A., et al. (2007). Memory and phonological awareness in children with benign Rolandic epilepsy compared to a matched control group. Epilepsy Research, 75(1), 57-62.
Oostrom, K. J., van Teeseling, H., Smeets-Schouten, A., Peters, A. C., \& Jennekens-Schinkel, A. (2005). Three to four years after diagnosis: cognition and behaviour in children with 'epilepsy only'. A prospective, controlled study. Brain, 128(Pt 7), 1546-1555.

Pera, M. C., Brazzo, D., Altieri, N., Balottin, U., \& Veggiotti, P. (2013). Long-term evolution of neuropsychological competences in encephalopathy with status epilepticus during sleep: a variable prognosis. Epilepsia, 54, 77-85.

Pujar, S. S., Martinos, M. M., Cortina-Borja, M., Chong, W. K. K., De Haan, M., Gillberg, C., et al. (2018). Long-term prognosis after childhood convulsive status epilepticus: a prospective cohort study. Lancet Child and Adolescent Health, 2(2), 103-111. https://doi.org/ 10.1016/S2352-4642(17)30174-8.

Reijs, R. P., van Mil, S. G., van Hall, M. H., Arends, J. B., Weber, J. W., Renier, W. O., \& Aldenkamp, A. P. (2006). Cryptogenic localization-related epilepsy with childhood onset: the problem of definition and prognosis. Epilepsy and Behavior, 8(4), 693-702. https://doi.org/10.1016/j.yebeh.2006.03.004.

Ricci, M., Mohamed, A., Savage, G., \& Miller, L. A. (2015). Disruption of learning and long-term retention of prose passages in patients with focal epilepsy. Epilepsy and Behavior, 51, 104-111. https:// doi.org/10.1016/j.yebeh.2015.06.016.

Ricci, M., Wong, T., Nikpour, A., \& Miller, L. A. (2019). Testing the effectiveness of cognitive interventions in alleviating accelerated long term forgetting (ALF). Cortex, 110, 37-46. https://doi.org/10. 1016/j.cortex.2017.10.007.

Rzezak, P., Guimaraes, C. A., Fuentes, D., Guerreiro, M. M., \& Valente, K. D. (2012). Memory in children with temporal lobe epilepsy is at least partially explained by executive dysfunction. Epilepsy \& Behavior, 25(4), 577-584. https://doi.org/10.1016/j.yebeh.2012.09. 043.

Rzezak, P., Guimaraes, C. A., Guerreiro, M. M., \& Valente, K. D. (2017). The impact of intelligence on memory and executive functions of children with temporal lobe epilepsy: Methodological concerns with clinical relevance. European Journal of Paediatric Neurology, 21(3), 500-506. https://doi.org/10.1016/j.ejpn.2016.12.010.

Sekeres, M. J., Bonasia, K., St-Laurent, M., Pishdadian, S., Winocur, G., Grady, C., \& Moscovitch, M. (2016). Recovering and preventing loss of detailed memory: differential rates of forgetting for detail types in episodic memory. Learning and Memory, 23(2), 72-82. https://doi.org/10.1101/lm.039057.115.

Sekeres, M. J., Moscovitch, M., \& Winocur, G. (2017). Mechanisms of memory consolidation and transformation. In N. Axmacher \& B. Ratsch (Eds.), Cognitive neuroscience of memory consolidation (pp. 17-44). Cham: Springer.

Smith, M. L., \& Lah, S. (2011). One declarative memory system or two? The relationship between episodic and semantic memory in children with temporal lobe epilepsy. Neuropsychology, 25(5), 634-644. https://doi.org/10.1037/a0023770.

Smith, M. L., Elliott, I., \& Naguiat, A. (2009). Sex differences in episodic memory among children with intractable epilepsy. Epilepsy and Behavior, 14(1), 247-249. https://doi.org/10.1016/j.yebeh.2008.08. 010.

Squire, L. R., \& Knowlton, B. J. (1997). Memory, hippocampus, and brain systems. In M. S. Gazzaniga (Ed.), The cognitive neurosciences (pp. 825-837). London: Bradford.

Swanson, H. L., Xinhua, Z., \& Jerman, O. (2009). Working memory, short-term memory, and reading disabilities: a selective metaanalysis of the literature. Journal of Learning Disabilities, 42(3), 260-287. https://doi.org/10.1177/0022219409331958.

Szabo, C. A., Wyllie, E., Stanford, L. D., Geckler, C., Kotagal, P., Comair, Y. G., \& Thornton, A. E. (1998). Neuropsychological effect of temporal lobe resection in preadolescent children with epilepsy. Epilepsia, 39(8), 814-819.

Tulving, E. (1972). Episodic and semantic memory. Organization of Memory, 1, 381-403. 
Vago, C., Bulgheroni, S., Franceschetti, S., Usilla, A., \& Riva, D. (2008). Memory performance on the California Verbal Learning Test of children with benign childhood epilepsy with centrotemporal spikes. Epilepsy and Behavior, 13, 600-606.

van Iterson, L. (2017). iter-SEIN Verhalenleertest. Handleiding Experimentele versie (iter-SEIN Story Learning Test. Experimental Manual). (unpublished version SEIN, Heemstede, Netherlands).

van Iterson, L., \& de Jong, P. F. (2018). Development of verbal short-term memory and working memory in children with epilepsy: developmental delay and impact of time-related variables. A cross-sectional study. Epilepsy and Behavior, 78, 166-174. https://doi.org/10.1016/ j.yebeh.2017.10.018.

van Iterson, L., Augustijn, P. B., de Jong, P. F., \& van der Leij, A. (2013). Establishing reliable cognitive change in children with epilepsy: the procedures and results for a sample with epilepsy. Journal of Psychoeducational Assessment, 31(5), 448-458.

van Iterson, L., Zijlstra, B. J., Augustijn, P. B., van der Leij, A., \& de Jong, P. F. (2014). Duration of epilepsy and cognitive development in children: a longitudinal study. Neuropsychology, 28(2), 212-221. https://doi.org/10.1037/neu0000034. van Iterson, L., Huber-Mollema, Y., Rodenburg, R., \& Augustijn, P. B. (2015). Short forms of the Wechsler Intelligence Scales for Children (WISC-III) in paediatric epilepsy; are results reliable? Epilepsia, 56(Suppl. 1), 98.

Wechsler, D. (1984). WMS-R: Wechsler Memory Scale-Revised: Manual: Psychological Corporation.

Wechsler, D. (2005). WISC-III ${ }^{N L}$. Wechsler Intelligence Scale for Children. Derde editie NL. Handleiding en Verantwoording. London: The psychological corporation / Nederlands Dienstencentrum NIP.

Wechsler, D. (2009). WPPSI-III-NL Nederlandstalige bewerking: Afname-en scoringshandleiding [Dutch version of the WPPSI-IIINL: administration and scoring manual]. Amsterdam: Pearson Assessment and Information BV (Dutch adaptation by: Hendriksen J \& Hurks P, 2009).

Wechsler, D. (2018). WISC-V-NL Wechsler Intelligence Scale for Children-V. Amsterdam: Pearson.

Publisher's Note Springer Nature remains neutral with regard to jurisdictional claims in published maps and institutional affiliations. 